\title{
A Strategic Roadmap for the Manufacturing Industry to Implement Industry 4.0
}

\author{
Javaid Butt $\mathbb{D}$
}

Faculty of Science \& Engineering, Anglia Ruskin University, Chelmsford CM1 1SQ, UK; javaid.butt@anglia.ac.uk

Abstract: Industry 4.0 (also referred to as digitization of manufacturing) is characterized by cyber physical systems, automation, and data exchange. It is no longer a future trend and is being employed worldwide by manufacturing organizations, to gain benefits of improved performance, reduced inefficiencies, and lower costs, while improving flexibility. However, the implementation of Industry 4.0 enabling technologies is a difficult task and becomes even more challenging without any standardized approach. The barriers include, but are not limited to, lack of knowledge, inability to realistically quantify the return on investment, and lack of a skilled workforce. This study presents a systematic and content-centric literature review of Industry 4.0 enabling technologies, to highlight their impact on the manufacturing industry. It also provides a strategic roadmap for the implementation of Industry 4.0, based on lean six sigma approaches. The basis of the roadmap is the design for six sigma approach for the development of a new process chain, followed by a continuous improvement plan. The reason for choosing lean six sigma is to provide manufacturers with a sense of familiarity, as they have been employing these principles for removing waste and reducing variability. Major reasons for the rejection of Industry 4.0 implementation methodologies by manufactures are fear of the unknown and resistance to change, whereas the use of lean six sigma can mitigate them. The strategic roadmap presented in this paper can offer a holistic view of phases that manufacturers should undertake and the challenges they might face in their journey toward Industry 4.0 transition.

Keywords: Industry 4.0; design for six sigma; lean six sigma; additive manufacturing; augmented reality; simulation; autonomous robots; internet of things; cloud computing; big data analytics; cyber security; horizontal and vertical integration

\section{Introduction}

Industrial revolutions are characterized by a major shift in the technological landscape. To date, humans have experienced four industrial revolutions. The first one came in the form of mechanization, the second one brought electrical energy, and the third revolution brought forth the rise of electronics, telecommunications, and, of course, computers [1]. The first three industrial revolutions spanned almost 200 years. The fourth industrial revolution, called Industry 4.0, stems from its German equivalent 'Industrie 4.0' in 2011 [2]. The terminology 'Industry 4.0' is new, but its enabling technologies, which are shown in Figure 1, have been around for decades and have massively benefitted several industries. Industry 4.0 is characterized by cyber physical systems that allow for the merging of real and virtual worlds in real time [3-6]. The implementation of Industry 4.0 technologies can offer significant benefits to the manufacturing value chain. These benefits include, but are not limited to, improved productivity and efficiency, increased knowledge sharing and collaborative working, flexibility and agility, easier compliance with regulations, better customer experience, reduced costs, and higher revenues $[7,8]$. Considering these benefits, Industry 4.0 is gaining attention from academia, research organizations, businesses, and even governments. Every country with manufacturing expertise is funding initiatives that can position them as promoters of advanced manufacturing facilities [9]. The focus, however, differs, 
with the European countries, UK, and USA being focused on developing business and standardization models [9-11], and countries like Japan, Germany, and China implementing digitalization, to increase efficiency and product quality, as well as reduce costs [12,13]. For example, a project funded by the European Union entitled 'Growing into Industry 4.0-Accelerate growth in manufacturing SMEs' aims to identify barriers to the uptake of Industry 4.0 in SMEs and propose different management related tools for ease of transformation [14]. The Australian government signed a cooperation agreement with Germany's Industrie 4.0 platform, to research reference architectures, standards, test laboratories, education, and training [15].

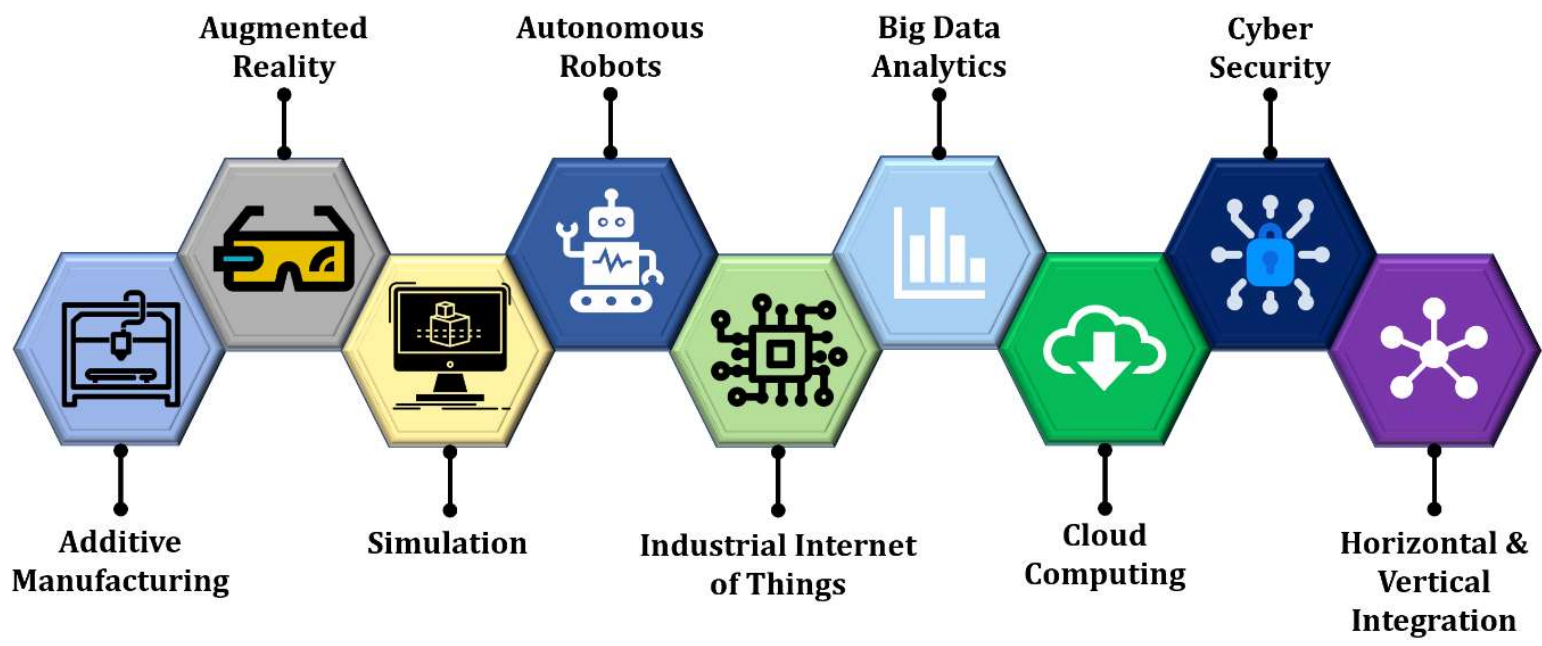

Figure 1. Enabling technologies of Industry 4.0.

There is no universally accepted definition of Industry 4.0. Therefore, Hermann, Pentek, and Otto [16] defined Industry 4.0 in terms of cyber physical systems, internet of things, internet of services, and smart factory. They proceeded to utilize this definition to propose six design principles that can support companies in identifying and implementing Industry 4.0 scenarios. These are interoperability, virtualization, decentralization, real-time capability, service orientation, and modularity. Interoperability refers to the ability of systems and workforce in a business to communicate, exchange data, and coordinate activities. Virtualization is linked to the monitoring of physical processes either by one virtual resource from multiple physical resources or multiple virtual resources from one physical resource. Decentralization refers to the transition toward system components rather than a central system to mitigate risks and instill flexibility of operations. Real-time capability means the collation and processing of data in real time that allows informed and timely decision-making. The ability to use big data analytics to obtain a predictive analysis that can help in better understanding the customers' needs is referred to as service orientation. Modularity refers to the ability of businesses to flexibly adapt to changing requirements and industry needs [17]. It is worth noting that there is a lack of readiness among companies toward not only Industry 4.0 adoption but its implementation. It is one thing to decide to adopt Industry 4.0 and an entirely different task to implement it properly, considering that there are no standardized approaches available. It is important to first highlight the challenges to Industry 4.0 adoption and then move to the implementation. The challenges to adoption include, but are not limited to, low understanding of Industry 4.0 implications, lack of knowledge and unified leadership, inability to accurately estimate return on investment, legal issues, data ownership, lack of digital culture, lack of digitally competent workforce, lack of infrastructure and internet-based services, reluctant behavior toward Industry 4.0, security issues, and financial constraints [18,19]. These are complex problems, and they become more challenging when moving toward the implementation of Industry 4.0 .

From both strategic and technologic perspectives, Industry 4.0 implementation requires a comprehensive strategic roadmap that visualizes every step on the journey toward an entirely 
digital manufacturing enterprise [20]. Researchers have used some means of proposing Industry 4.0 implementation through strategic plan [21], maturity level-based model [22], and outcome-based business model [23]. The main problem with these approaches is that they are new to the manufacturing organizations and can face resistance due to the reluctance of the workforce to change its ways. Industry 4.0 is not just hype, and manufactures should strategically embrace it to remain competitive in the market. Technological innovations affect the vision and goals of a business and require a strategic plan to ensure not only their implementation but the smooth running of operations as a result of them [24]. Companies utilize road mapping as a tool that can help plan activities and deliver on potential benefits of technological advancements. This shows that there is a need for a strategic roadmap that can support the implementation of Industry 4.0 transformation and one that is not ignorantly opposed by the workforce due to lack of expertise.

This paper presents a strategic roadmap that can be used by manufacturing organizations as a reference framework for successful transition from traditional manufacturing into Industry 4.0. Having a deep understanding of Industry 4.0 enabling technologies is a prerequisite for development of the strategic and technological roadmap. Therefore, Section 2 presents a review on the impact of Industry 4.0 enabling technologies, with the help of manufacturing-focused literature. Section 3 discusses the strategic roadmap for Industry 4.0 implementation and Section 4 highlights the phases as well as the associated challenges.

\section{Applications of Industry 4.0 Enabling Technologies}

\subsection{Additive Manufacturing}

This is an umbrella term that encompasses several methods capable of manufacturing 3D products by adding layers on top of each other [25]. The very first additive manufacturing (AM) method came into existence in the 1980s, and since then these processes have increased in numbers, functionality, and uses in the manufacturing sector [26]. There are seven categories of AM, i.e., vat photopolymerization, powder bed fusion, binder jetting, material jetting, sheet lamination, material extrusion, and directed energy deposition [27]. AM can produce complex geometries, reduce manufacturing costs, and fabricate parts with premium materials with small production runs and short turnaround times [28,29]. AM allows the realization of advanced part designs that provide additional space, multifunctional parts, multi-material parts, part consolidation, and parts that are difficult to machine [30-32]. AM methods have been extensively researched for optimization of process parameters, new materials usage, development of new processes, improvements to existing processes, material properties of products, standardization, and material modeling [33-36]. Based on these attributes, AM is widely utilized by several manufacturing sectors, including, aerospace, automotive, construction, medical, and consumer goods.

In the aerospace sector, AM has been in use by companies such as Airbus and GE (General Electric) for decades. For metal parts, the main AM technologies in aerospace applications are directed energy deposition and powder bed fusion. For nonmetallic parts, the dominant AM technologies are vat photopolymerization, material jetting, and material extrusion. Yakout et al. [37] discussed the manufacture of Invar 36 (UNS K93600) using selective laser melting by identifying the optimal process parameters. This material has a low coefficient of thermal expansion and can be extremely beneficial for the aerospace industry. They investigated the effects of laser power, scanning speed, point distance, exposure time, hatch spacing, stripe width, stripe overlap, beam offset, and layer thickness on the density, microstructure, and surface features of the products. Like the aerospace industry, the automotive industry also exploits similar benefits from AM. Lightweight and aerodynamically optimized products can help reduce fuel consumption and drag. Böckin and Tillman [38] conducted a life-cycle assessment for metal parts of an engine in a light distribution truck. They compared powder bed fusion (PBF) with subtractive manufacturing (SM) and showed that PBF could improve life-cycle environmental performance by redesigning components for weight reduction, leading to lower fuel 
consumption by the engine compared to SM. However, it would require a clean electricity source, the capability to build large products, and low-impact raw materials, to stay viable in the industry.

The use of AM for construction offers added benefits to the users, such as worker safety, especially in harsh environments, and shrinkage of supply chain, as customized large structures can be manufactured on-site, rapidly, without the need for multiple suppliers. This area is also called large-scale additive manufacturing and comprises several methodologies that make use of robotic arms for material deposition, including contour crafting [39], cellular fabrication [40], d-shape [41], and concrete printing [42]. Keating et al. [43] presented the Digital Construction Platform (DCP) based on AM comprising a compound robotic arm framework made from water-powered and electric mechanical arms carried on a tracked mobile platform. They built an arch formwork structure that was $14.6 \mathrm{~m}$ across and $3.7 \mathrm{~m}$ tall; it was effectively additively produced on-site, with a development time under $13.5 \mathrm{~h}$. Such a construction can offer benefits in safety, quality, customization, speed, cost, and functionality. To tackle global homelessness, a US-based non-profit organization New Story is working with ICON to build 30 homes in Tabasco, Mexico, using AM [44]. AM has also made an enormous impact on the global economy, and the development of inhabitable structures is just another example where AM is working toward benefiting society. A recent issue that has caused a serious global health crisis is the outbreak of COVID-19. Large-scale AM also played a role in alleviating some of the issues faced by healthcare professionals. The Chinese Construction Company WinSun deployed 3D-printed isolation wards to the hospitals in the Wuhan region, to house medical staff, using their large-scale 3D construction prints. These wards were modified to suit the needs of isolation standards and could withstand extreme environmental conditions [45].

The use of AM in the medical sector has increased exponentially over the years for medical models, surgical implants, surgical guides, external aids, and bio-manufacturing. Popovich et al. [46] used selective laser melting to manufacture a patient-specific hip implant from Ti-6Al-4V powder, according to the data acquired via computed tomography. Design freedom offered by AM allowed the design of a texturized surface for the implant that could improve the osseointegration process. They also applied a post-process called annealing, by heating the implant, and managed to significantly increase its tensile strength. In addition to the research-intensive AM investigations, there are also instances of AM being used as a catalyst to accelerate production to benefit society. This has been demonstrated with the AM community from around the world coming together to support the medical professionals in their fight against COVID-19. AM has emerged as a supply-chain enabler and is providing products in mass quantities, including PPE (personal protective equipment), such as face masks and shields; medical testing kits, such as swabs; medical-device components, such as ventilator valves; and ecosystem components, such as hands-free door openers. AM experts, designers, and providers are responding to the global crisis by volunteering their respective skills to ease the pressure on supply chains and governments. Companies are making their designs freely available. SMEs, large corporations, and governments alike are setting up AM networks, with specified objectives to manufacture medical-grade equipment for medical professionals [47]. This discussion highlights the significant impact of AM on our manufacturing industry.

\subsection{Augmented Reality}

In the context of Industry 4.0, the use of augmented reality (AR) is extremely beneficial, as it provides ease and flexibility of operation. AR is often confused with virtual reality (VR), but they are two different technologies. AR overlays information and digital content on the real world, in real time, using a display piece or eyeglasses, whereas VR allows users to put on a headset and delve into a virtual world [48-50]. The use of AR is becoming widespread in the manufacturing sector, for a multitude of reasons. Most common AR technologies include AR markers [51], displays and hologram technologies [52], mobile devices [53], tracking technologies [54], and interaction technologies [55]. $\mathrm{AR}$ is revolutionizing the manufacturing industry by offering better insights for product development, 
equipment maintenance, workforce training, production floor issues, process flow, complex assembly, expert support, quality assurance, and automation [56,57].

Visual computing is an umbrella term that encompasses computer graphics and media technologies for future smart factories. Posada et al. [58] analyzed the role of visual computing in supporting operators in Industry 4.0. They described the challenges faced by operators in smart factories and enabling technologies to mitigate them. For example, operators can be trained to perform tasks by using AR assistance for human-machine interaction; the decision-making of the operators can be supported by using digital twins, as well as multi-screen dashboards, and learning from the activities of operators through video-based deep learning and media monitoring of the manufacturing execution system. Similarly, Segura et al. [59] employed the concept of Operator 4.0 with visual computing (VC). They presented a framework with practical examples and concluded that VC technologies can positively contribute to the enhancement of operator ability to perform traditional tasks. Makris et al. [60] utilized AR to support production engineers and shop-floor operators in generating and using assembly instructions, respectively. The methodology allowed the workers to operate faster and reduced their cognitive load, leading to increased efficiency of operation. Uva et al. [61] designed a prototype for spatial augmented reality (SAR) to be used in manual assembly lines. They compared the effectiveness of operation between the SAR and paper data transfer. They tested the SAR prototype on a motorbike engine and showed an improvement in performance and reduction of error rates. Molineros and Sharma [62] proposed augmenting a data stream based on process graphs for guiding manual assembly. They showed that such a mechanism can improve the workers by instilling skills acquired by doing the work that would otherwise require specialized knowledge. Doshi et al. [63] discussed the use of a projector-based spatial AR system for quality assurance. This system was set up at the General Motors (GM) Holden plant in Elizabeth, Australia, and was used to assess the quality of manually spot-welded locations on Holden Cruze vehicles. They reported a $52 \%$ decrease in standard deviation, leading to a higher degree of precision and accuracy of operation by the workers, based on the visual AR cues. Zhou et al. [64] discussed the use of spatial augmented reality and head-mount displays for spot-weld inspections in automotive manufacturing. They reported a significant increase in efficiency of the operators because of the information being available at the right time and at the right place, instead of paper-based instructions that are quite ineffective.

The development of digital twins is gaining mainstream attention, as they allow real-time monitoring and control of a physical asset through a virtual digital replica. Zhu, Liu, and Xhu [65] developed a digital twin of a CNC milling machine and utilized HoloLens to augment the data. The AR application gives the user the ability to monitor and control the machine, as well as interact and manage the digital twin data simultaneously. Such an integration can prove to be useful for intelligent process control applications in the future for more complex systems. On the other hand, Lee [66] integrated AR with stochastic Petri net model to develop an AR labeling architecture for real-time modeling and simulation of large-scale manufacturing environments, resulting in improved layout design and simulation analysis. Blaga and Tamas [67] integrated AR with a cobot (collaborative robot), a see-through device, a digital twin, and an algorithm for assembly visualization. They demonstrated the effectiveness of this setup for superimposing augmented data on physical product, with a good degree of accuracy, showing its potential for improving manufacturing processes. These examples illustrate that AR is extremely beneficial for the manufacturing industry, but its value increases as other techniques are integrated with it, such as digital twins and cobots.

\subsection{Simulation}

A simulation is an approximation based on established mathematical models or statistical tools to show the behavior of a product or a process using graphics [68]. Simulations provide users the freedom to experiment with different conditions and observe the results to make informed decisions. However, there is a need to validate the simulations with an acceptable error percentage for use in real-world scenarios [69]. Their popularity stems from the advancement in simulation packages with more 
sophisticated algorithms and appealing graphics. A simulation can be used for a product or a process or a process flow, and there are several software packages that work for both scenarios. Products and manufacturing processes are usually simulated based on numerical analysis methods, such as FEM (Finite Element Method), FVM (Finite Volume Method), and DEM (Discrete Element Method). Some software packages for such simulations used in the manufacturing industry are CAEplex, MATLAB, Ansys, OpenFOAM, EMS, SolidWorks Simulation Premium, COMSOL Multiphysics, Flow-3D, and ProModel Optimization Suite. On the other hand, manufacturing-process-flow simulation packages are based on various modeling paradigms, including discrete event or process-centric, systems dynamics, petri net, Monte Carlo simulations, and agent-based. These packages include but are not limited to WITNESS, AnyLogic, FlexSim, iGrafx, Simio, SimSci, and Simul8 Professional. They can provide animated and interactive models to replicate the operation of an existing or proposed production facility. They can help solve common manufacturing challenges that include assessing the impact of investment, production planning optimization/scheduling, facility designing, manufacturing capability planning, process improvement, bottleneck analysis, production line balancing, resource allocation, improve material flow and inventory planning, experimentation with lean manufacturing techniques, and, last but not least, plan Industry 4.0 approaches [70-72].

The use of appropriate optimization methodologies for simulations is useful, as it saves computational times and provides more realistic results. Al-Tamimi et al. [73] conducted topology optimization based on the solid isotropic microstructure with penalization method to design fixation plates used in the case of a bone fracture. They reduced the plate volume to ensure that stress levels were comparable with the bone, to avoid bone stress shielding under different loading conditions. They utilized Solidworks and successfully implemented topology optimization, to design less-stiff and lightweight fixation plates, reducing the stress shielding effect, promoting load transfer to the bone, and thus contributing to bone remodeling. Grivc, Deržič, and Muhič [74] analyzed a divided rail freight brake disc crown used in rail freight wagons. They conducted a numerical analysis for the optimization of its thermal dissipation properties and reduction of ventilation losses, using Ansys CFX. Their investigation reported $37 \%$ reduction in ventilation losses and $21 \%$ reduction in mass, resulting in better thermal performance that would potentially provide significant energy savings. Migliaccio et al. [75] designed a novel injector with a hollow cone nozzle (HCN) that could provide low emissions for automotive engines. They analyzed this design by using OpenFOAM, which provided valuable insight into the spray penetration and diffusion behavior of the HCN that were otherwise extremely challenging to observe.

For the process flow, various quality management philosophies and methodologies can be implemented to improve the process, and the use of simulations can show the results virtually, before physical implementation. Concepts such as lean manufacturing, six sigma, and total quality management are popular in the manufacturing sector [76]. In that context, the work done by Khan et al. [77] explored the capabilities of WITNESS Horizon to simulate a valve manufacturing facility and implemented Khan-Hassan-Butt (KHB) process re-engineering methodology for its optimization. They showed an increase of $20 \%$ in production output as a result of their proposed methodology that can identify process interdependencies and can be used with structured, as well as semi-structured, data. Stadnicka and Antonelli [78] simulated the production of rubber-metal sleeves for a car frame with the existing value stream map and the optimized value stream map using FlexSim based on the discrete event methodology. They successfully optimized various process parameters and showed the importance of computer simulations in value stream analysis that can help in making effective decisions pertaining to the improvement and development of a manufacturing process. Avventuroso, Silvestri, and Frazzon [79] used Anylogic to conduct a simulation-based analysis to support planning, designing, and performance evaluation of an AM plant for large-scale production of medical devices. They modeled a pilot plant in the software based on liquid frozen deposition manufacturing and optimized the production flow by modifying the number of printers, clusters, gelation stations, and employees. The use of computer simulations can help support effective 
decision-making by allowing the user to evaluate the pros/cons of a given configuration to achieve maximum production output.

\subsection{Autonomous Robots}

This is a crucial piece of the Industry 4.0 puzzle and is widely utilized in the manufacturing industry. An autonomous robot is characterized by possessing a degree of autonomy to perceive and respond to external stimuli on its own [80]. A typical robot offers a multitude of benefits to humans, such as performing repetitive, dangerous, and time-consuming tasks, higher accuracy, increased efficiency, reduced errors, and more operational time, as there is no need for breaks. An autonomous robot adds to these lists of benefits by including intelligence, meaning that it does not require human control and can make its own decisions based on the programming [81]. To take advantage of these benefits, a special class of robots has been defined known as cobots or collaborative robots [82]. They share workspace or work near humans, to help perform their tasks efficiently. Pioneered by KUKA (Germany) and Universal Robots (Denmark), these robots operate differently. Rather than be programmed to a specific set of steps, using programming tools, many cobots are trained by humans manipulating the arms and training by example. A human would move the robot, and the robot would store the movements in its memory. This also negates the use of specialized skills for robot programming and gives the control to the operator on the production floor. According to the International Federation of Robotics [83], there are four types of collaborative manufacturing applications, i.e., co-existence (human and robot work together, but no shared space), sequential collaboration (human and robot work together on a part separately but not at the same time), co-operation (human and robot operating at the same time on a part or machine), and responsive collaboration (robot responds to the human movements in real time). These cobots are gaining popularity in the manufacturing industry and are governed by several international standards in terms of their design, use, and protective measures [84-86].

In terms of the applicability of cobots, Fast-Berglund et al. [87] evaluated the potential of using UR3 and UR5 robots (from Universal Robots, Denmark) for the assembly of O-rings being used by a medium-sized company called CEJN AB (Sweden). They also utilized two automation strategies, i.e., DFA2 and DYNAMO++ for the operation. They concluded that cobots can provide significant improvements in quality and reductions in cycle time. However, they emphasized the need for the development of more standards, to ensure consistent application and results. Cherubini et al. [88] developed a collaborative human-robot manufacturing cell for homokinetic joint assembly. They manipulated the robot to switch between active and passive modes, depending on the needs of the operator. They reported a significant reduction in the operator's workload and risk of injuries. They also predicted that such a system, if deployed in the automotive industry, could have a payback period of 12 months (based on estimates). Sadik and Urban [89] proposed a distributed control solution combining an ontology-based multi-agent system and a business rule management system for co-operative manufacturing. They focused on manufacturing knowledge representation, sharing, and reasoning among the operator, robot, and surrounding production components. The proposed methodology allowed for a collective decision-making that can be adapted based on the requirements effectively. Meziane, Otis, and Ezzaidi [90] devised a neural-network-based supervised-learning protocol to improve collision-free motion planning during shared production activities between a human and a robot. They also applied an optimal trajectory of motion that can easily navigate in a dynamic working environment. Like augmented reality (Section 2.2), cobots or autonomous robots work well on their own. However, the integration of automation strategies could significantly improve their performance. All in all, cobots are aimed at augmenting what humans do, to make humans more effective, efficient, and enhanced. This is the reason for their widespread adoption by the manufacturing industry that has only shown concern mainly on the safety front but is satisfied with other aspects of their operation and application [91,92]. 


\subsection{Industrial Internet of Things}

The interconnectivity of sensors, equipment, machines, and internet is termed as internet of things [93]. Its usage in the industry to additionally connect supply chains, data, and people has morphed the term into industrial internet of things (IIoT). The manufacturing industry is the biggest beneficiary of IIoT [94]. The major adoption drivers for IIoT in the manufacturing sector include cost reduction, shorter time to market, mass customization, and improved safety [95]. IIoT has a multitude of applications in the manufacturing industry. Their use case segments include, but are not limited to, connected factory, asset management, facility management, logistics, customer preferences, predictive maintenance, quality control, and production flow monitoring [96]. The use of IIoT results in a complete digital transformation, allowing for a better interconnected production system that is capable of running and maintaining itself $[97,98]$. Its impact is undeniable and can be summarized in three dimensions, i.e., visibility into production floor and field operations, visibility into manufacturing supply chain, and visibility into remote and outsourced operations [99]. The use of sensors on equipment and their interconnectivity through sophisticated protocols lend their way to the development of cyber-physical systems [100,101] and digital twins [102,103] that can amplify the benefits of IIoT. Other Industry 4.0 enabling technologies, such as big data analytics, cloud computing, and cyber security, are used in combination with IIoT, to serve the manufacturing industry. In addition to providing substantial benefits, there are also challenges associated with the adoption of IIoT, such as high initial costs and uncertainty about the return on investment, data security and privacy issues, lack of qualified employees, integration with the legacy systems, inability to perform rapid experimentation, and lack of established standards [104].

IIoT affects several facets of the manufacturing sector, including business models, production, supply chain, and customers. Kiel, Arnold, and Voigt [105] provided a systematic framework to investigate the influence of IIoT on established manufacturing business models. They reported the value of production and process optimization offered by IIoT by emphasizing the importance of customers in the decision-making process that can promote positive changes to the business models. Gierej [106] proposed an outcome-based business model that can support companies toward a smooth digital transition with IIoT. The model helps in moving with the old concepts being used by manufacturing companies for decades and gradually integrates the digital features. Yerra and Pilla [107] utilized IIoT in an automotive composites body shop, to optimize the material flow, to reduce cycle times and reduce operational costs. They used computer simulations to compare the production times of the existing and the proposed interconnected IIoT-based system, with the latter removing $19.3 \mathrm{~h}$ from the process. Vita et al. [108] used the FASTEN open IIoT architecture on the Metallic Centre Wing Assembly Line at the Embraer Aerospace facility in Évora, Portugal, to improve productivity and agility, as well as predict equipment failures. They reported that their IIoT-based decision support system can accelerate decision-making and enhance production.

Arnold and Voigt [109] conducted a mixed-methods investigation for IIoT adoption by manufacturing companies. They reported on the various ecosystem dimensions of the business, such as customers, suppliers, external organizations, and research institutions. Their results showed a slight concern on the part of the customers and suppliers but a higher degree of cooperation with external organizations and research institutions. IIoT enables perpetual connectivity with customers. This is both a pro and a con, as it can allow for faster feedback for new products or design demands but can lead to the customers developing unrealistic expectations [110]. Value stream mapping (VSM) is a useful tool for lean manufacturing, and the incorporation of IIoT can broaden its usage with real-time data from multiple sources, leading to effective decision-making. Balaji et al. [111] incorporated IIoT to develop a dynamic VSM capable of collating large datasets for analysis, such as bottlenecks identification and process-flow optimizations. To exploit the benefits of IIoT, an Industrial Internet Consortium (IIC) was established in 2014, comprising industrial, government, and academic partners from around the world, to accelerate the growth of IIoT by identifying, assembling, testing, and promoting best practices [112]. 


\subsection{Big Data Analytics}

The most vital aspect for any business is its data. The data allow a business to work smoothly, incorporate modifications for improvements, and plan future developments. With the use of IIoT, more data are being collated than ever before from sensors connected to machines, transfer of data for communication, human-machine interaction, and recording each interaction. Analyzing such copious amounts of data is challenging, and this is what big data analytics (BDA) can do for different industrial sectors. Big data can analyze large datasets that are challenging to be processed by conventional data-processing software packages and can extract useful information. The manufacturing industry is a prime example where BDA has made a mark by providing beneficial insights and being able to generate useful information [113]. BDA refers to the utilization of statistics and other mathematical tools for business data, to assess and improve existing practices. In manufacturing, analytics can be used to examine historical process data, identify patterns and relationships among discrete process steps and inputs, and optimize the process parameters for maximum output. Manufacturing companies all over the world are focusing on developing real-time production floor data and strategies for their use to conduct sophisticated statistical assessments for enhancing yield and transition toward smart manufacturing. In terms of its attributes, big data was first defined with three V's, i.e., volume, velocity, and variety [114]. Over the years, however, more attributes have been added, such as veracity, variability, volatility, and value, to make it seven V's [115]. There are currently 42 V's identified for big data [116] that goes to show a higher sophistication level. In addition to the V's, big data is characterized by four data types [117], i.e., structured (having a defined format and easy to analyze), semi-structured (having some patterns and moderately easy to analyze), quasi-structured (Having an erratic format, requires specialized tools and is difficult to analyze), and unstructured (having no conceivable structure and extremely challenging to analyze).

The value of big data becomes evident when it is used as a tool for decision-making processes. BDA can improve the decision-making process and enhance production numbers by employing other tools, such as artificial intelligence, algorithms, and databases. Knowledge-based and intelligent-information approaches are required to make sense of the data and use it for better performance of cyber-physical systems [118]. Furthermore, engineering standards can also be employed for domain modeling in virtual engineering, to discover implicit knowledge that can be beneficial for engineers [119]. By making sense of the copious amounts of data gathered through various means, BDA can perform four types of analytics, i.e., descriptive, inquisitive, predictive, and prescriptive [120]. Descriptive analytics provide hindsight on the existing state of a business situation, using business intelligence tools [121]. Inquisitive analytics use descriptive analytics to find out why something happened, by identifying root causes [122]. Predictive analytics provide a glimpse of the future state of the business by analyzing historical data [123]. Prescriptive analytics define a sound course of action based on the output of the predictive analytic models [124]. These different analytics are extremely useful to the manufacturing industry, as they help in product/process/supply chain optimization, automatic quality testing, predictive/preventive maintenance, risk management, data-drive enterprise growth, and tracking of overheads/daily production [125].

It has been reported that BDA in manufacturing industry is set to exceed $\$ 4.5$ billion by 2025 [126], and this shows its tremendous growth and highlights the need for extensive research into sophisticated analytical tools. Zhong et al. [127] utilized BDA for physical internet-based logistics data, to develop intelligent manufacturing ship floors. They deployed radio-frequency identification readers, tags, and wireless communication networks on the production shop floors to collate data. They used these data to visualize the logistics trajectory and to evaluate the efficiency of logistics operators and operations. Moyne and Iskandar [128] used BDA to detect faults and predictive maintenance for the manufacture of semiconductors. They emphasized two aspects for better results, i.e., data quality and incorporation of subject-matter expertise in the analytics. They concluded that the data quality can improve drastically with the help of a digital twin, but the expertise aspect will remain a limitation in semiconductor manufacturing. O'Donovan et al. [129] presented an industrial big-data pipeline 
architecture that can support both the legacy and technologically advanced systems, to facilitate initial smart manufacturing efforts for large-scale manufacturing. They conducted the study in DePuy Synthes (Ireland) and reported on challenges, as well as desirable characteristics, that can facilitate BDA research in large-scale industrial environments. Mani et al. [130] conducted interviews in 3PL Logistics and SUMUL (Gujrat India), to identify and mitigate social issues in the supply chain. They incorporated BDA for data analysis, to mitigate social risks in manufacturing companies. The literature highlights the impact of big data analytics that can be further enhanced with the use of artificial intelligence and machine learning [131].

\subsection{Cloud Computing}

Several software packages are used in the manufacturing sector for everything ranging from simulations to resource management. Typically, such software packages or applications would be downloaded on a physical computer or in-house server. Cloud computing (CC) allows the use of these resources through the internet, to anyone with the proper authorization and access. CC refers to the on-demand availability of computer-system resources, especially data storage and computing power, without direct active management by the user. The National Institute of Standards and Technology (NIST) identified five key characteristics for CC, i.e., on-demand self-service, broad network access, resource pooling, rapid elasticity, and measured service [132]. CC offers several benefits to the manufacturing sector, including flexibility of operations (to cope with fluctuating demands), disaster recovery (by offering cloud-based backup and recovery protocols), automatic software updates (for smooth operations), low capital costs (by cutting out hardware), increased collaboration (by allowing real-time updates of documents), freedom of operation (by allowing the users to work from anywhere with an internet connection), document control (by streamlining the updates from different users in real-time), security of data (as defective hardware will not result in loss of data), and competitiveness (by having access to enterprise-class technology) $[133,134]$. Different service models are used by CC to serve its customer base, i.e., IaaS (infrastructure as a service) [135], PaaS (Platform as a Service) [136], SaaS (Software as a Service) [137], MBaaS (Mobile Backend as a Service) [138], FaaS (Function as a service) [139], and serverless cloud [140].

The integration of CC with other technologies, such as next-generation wireless, advanced sensors, high-performance computing, and computer-aided design, engineering, and manufacturing (CAD/CAE/CAM) software, represents an essential component of the smart manufacturing revolution. CC applications have impacted every aspect of modern manufacturing. One key aspect of its popularity is that both large corporations and SMEs can benefit from its capabilities on a subscription-based model, depending on their cash flow. CC and IoT also paved the way for a new paradigm in the manufacturing sector called cloud manufacturing (CM). It is defined as a smart networked model for manufacturing that embraces cloud computing, which aims to meet the increasing demands for higher product individualization, wider global cooperation, knowledge-intensive innovation, and rising market-response agility [141]. Liu et al. [142] developed a CM multitask scheduling model by incorporating task workload modeling, service efficiency coefficient, and service quantity. Their model allowed for the successful completion of more tasks within the time constraint, without adversely affecting quality. Jian and Wang [143] discussed an optimization model for batch CM, aimed at reducing costs and saving time. They focused on the issue of tasks scheduling in CM and showed the applicability of their model with the help of computer simulations. Lartigau et al. [144] proposed an optimization methodology for scheduling tasks in CM. They took into consideration a batch of tasks and quantity of resources, to highlight the scheduling challenges and show the applicability of their method.

In addition to the research on scheduling tasks in CM, the integration of different Industry 4.0 enabling technologies are also benefiting the manufacturing sector. Tao et al. [145] proposed a CC and IoT-based service system for CM. They discussed the relationship among CC, IoT, CM, and the resulting model, to highlight challenges and potential applications in this domain. Jin, Yao, and 
Chen [146] presented a correlation-aware CM service model to characterize the quality of service (QoS) dependence of an individual service on other related services. They showed good applicability results of their model and discussed its limitations (increment of the percent of correlation cloud services), as well. Tao et al. [147] developed a novel parallel intelligent algorithm called full connection based parallel adaptive chaos optimization with reflex migration, to address the issue of service composition optimal selection in CM. Their proposed model showed a significantly higher efficiency in terms of searching capability and time efficiency, as compared to traditional serial intelligent algorithms and classical parallel intelligent algorithms. With the intensive research developing new models for $\mathrm{CM}$, there is also extensive literature available discussing the challenges of such models [148-150]. Therefore, it is imperative for manufacturing companies to weigh the pros and cons of CM models before implementation.

\subsection{Cyber Security}

The move to digitization, cyber-physical systems (CPS), interconnected devices, and real-time communication in the context of Industry 4.0 shines a spotlight on the generated data and its protection. Cyber security (CS) is rapidly becoming a major concern for manufacturers and consumers. CS is the combination of policies and practices employed by individuals and organizations, to monitor computers, networks, programs, and data and prevent them from being subject to unauthorized access or attacks for exploitation purposes [151,152]. Cyber risks can irreplaceably damage an organization, and the manufacturing sector is especially susceptible to risks such as intellectual property theft, data integrity issues, cyber-physical damages, safety of employees, and productivity losses $[153,154]$. There is also a need for standardization of cyber security protocols, to instill confidence in a user organization. The most common ones are ISO/IEC 27,001 and 27,002, part of the ISO/IEC 27,000 family of standards published by the International Organization for Standardization and the International Electrotechnical Commission [155].

The importance of cyber security cannot be overstated. This has led to extensive research where threats/attacks are planned and introduced into manufacturing systems, to analyze the extent of damage that can be done to both software and hardware, assess the capabilities of existing cyber control protocols, and assess the competence of individuals in identifying cyber threats. These attacks can affect products and processes, alter data, and deny services, leading to a significant loss of time and resources. For example, changing the product design could have catastrophic effects on its performance and functionalities. Quality-control systems are incapable of identifying malicious attacks and would simply reject the product for not satisfying the quality standards. Wells et al. [156] tested a cyber-attack by introducing a virus that can alter the toolpath of a three-axis milling machine for the manufacture of a tensile test sample. The participants of the experiment were able to assess that their sample was not made according to the proper dimensions, but no one was able to diagnose the problem as a cyber-attack. The researchers highlighted the lack of education and knowledge in identifying such attacks. Sturm et al. [157] introduced a cyber-attack on.STL file of an additive manufacturing system, as it is the most vulnerable. They placed a void inside a tensile test sample that could easily avoid detection through common practices. The void caused a $14 \%$ reduction in yield strength, showing the ease at which a defect can be introduced. They also presented recommendations to reduce such threats, such as improved software checks, hashing/secure signing, improved process monitoring, and operator training.

Vincent et al. [158] presented a novel product/process design approach to enable real-time attack detections, by introducing a trojan in the manufacturing process of integrated circuits. They incorporated structural health-monitoring techniques to detect changes in a part's intrinsic behavior and showed how trojans can be detected within a manufacturing process, to support traditional quality-control methods. DeSmit et al. [159] used intersection mapping to identify cyber-physical vulnerabilities in manufacturing systems. They implemented their approach at the Commonwealth Center for Advanced Manufacturing (USA) and were successfully able to identify the 
cyber vulnerabilities with a stoplight scale of low, medium, and high. Hutchins et al. [160] established a framework for identifying cyber threats by considering the data flow in automotive manufacturing. They showed several mechanisms for identifying vulnerabilities based on the data transfer and provided valuable insights for mitigation. These examples indicate research efforts on several fronts, such as identifying existing vulnerabilities, potential cyber-attacks, weaknesses of existing measures, awareness levels, and cyber-threat detection, as well as mitigation methodologies [161-163].

\subsection{Horizontal and Vertical Integration}

Like the other Industry 4.0 enabling technologies, the concept of horizontal and vertical integration has been benefitting the manufacturing organizations for years. However, its implementation with Industry 4.0 technologies elicits a different response, leading to greater gains. Stock and Seliger [164] outlined three dimensions for the Industry 4.0 paradigm, i.e., horizontal integration across the entire value creation network, vertical integration and networked manufacturing systems, and end-to-end engineering integration across the entire product life cycle. The aim of horizontal and vertical integration is to develop organization-wide protocols for data sharing, to create the basis for an automated supply and value chain. End-to-end engineering integration involves machine integration and customer integration as parts of the production system, along with product-to-service integration through direct manufacturer monitoring, focusing on product, production, and customer design [165]. One of the design principles of Industry 4.0 is interoperability, and its core idea is integration [166,167].

These three integrations have been in constant use by the manufacturing sector based on their advantages as singular entities or as a combination. In terms of singular use, Kim and Park [168] presented a horizontal integration approach to establish effective communication among a CPS, middleware, and production management system. They also discussed the limitations of the approach and proposed further research into improving stability, resource allocation, and performance analysis. Gerber, Bosch, and Johnsson [169] proposed a flexible communication architecture for a vertical integration that could allow manufacturing companies to directly connect their IT-Systems with their manufacturing plants. They tested their method at the SmartFactory-KL (Germany) by transferring information as key performance indicators to support decision-making and to close the gap between business and technical processes. Bicaku et al. [170] presented an end-to-end communication protocol for a cyber physical production system that can provide continuous improvement through smart algorithms and can identify dependencies among components, as well as provide an overview of the system's security.

As a combinational approach, the most common one is the combination of horizontal and vertical integration. Liu et al. [171] developed a cyber-physical production system at Experimental and Digital Factory at the Chemnitz University of Technology (Germany). They built a logistics system and implemented horizontal, as well as vertical, integrations. They showed the limitations in terms of the communication and testing of such an integration. Mazak and Huemer [172] presented an integrated modeling framework called HoVer, to develop a universal model-driven approach toward the horizontal and vertical integration, in the context of smart factories. They built a resource event agent business ontology [173], using concepts from ISA-95 [174] to apply the two integrations. Zhuo, Alvarez, and Feldmann [175] developed an integrated product model based on STEP and feature technology to implement horizontal and vertical integration of product data fitted to the needs of molded interconnect devices. Based on the effective integration, they established communication among the devices, simulation software, and the physical equipment for a superior operation.

Based on the amount of data generated by using IIoT and CPS, a combination of all three integrations is also becoming exceedingly popular. Foidl and Felderer [176] discussed these three integration protocols and used the DIN ISO 9000 quality-management-systems approach [177] to highlight challenges and opportunities for the quality management domain through the advent of Industry 4.0 in an Austrian electronic manufacturing company. Similarly, Zhou, Liu, and Zhou [15] incorporated the three integrations with the strategic planning of a CPS and devised 
system standardization and efficient management protocols. The literature highlights the capabilities of different integration approaches and their significance in the data-driven manufacturing sector.

\section{Industry 4.0 Roadmap Conceptualization}

The discussion provided in the preceding sections (Sections 2.1-2.9) pertaining to Industry 4.0 enabling technologies presents an in-depth literature review of their use in manufacturing. It is evident that Industry 4.0 has created value for the manufacturing industry in ways that were not even imaginable a few years ago. It has provided benefits such as increased productivity, reduction of product lead time, improvement of product quality, increased workforce efficiency, and an increase of process visualization, as well as control [178]. It is crucial to understand the impact to these enabling technologies, to ensure that their opportunities can be captured. This discussion is summarized in Table 1 and forms the basis for understanding the technological considerations for the development of the strategic roadmap. These opportunities paint a clear picture that shows how much value the manufacturing industry has derived from Industry 4.0 enabling technologies. However, there is still trepidation when it comes to adopting and implementing Industry 4.0, due to lack of standardized approaches. The manufacturing-focused literature review helps to understand what these enabling technologies can do and define strategies for their deployment. These strategies can be used as building blocks for the strategic roadmap, to ensure that every facet of a manufacturing organization has been considered and appropriate strategies have been defined for the implementation of Industry 4.0 enabling technologies.

The benefits offered by Industry 4.0 have created a ripple effect where organizations are strategically planning to move toward digital transformation to enhance their competitiveness in the market. However, this is not an easy task and requires a long-term commitment to ensure that a transition from the conventional to the digital has been made successfully. Adoption of Industry 4.0 would not only challenge a manufacturing company's capacity to innovate, but also requires new strategies, organizational models, organization-wide changes in physical infrastructure, manufacturing operations/technologies, human resources, management of practices, and change management [179]. This is a challenge for small/medium companies, and large organizations can also be overwhelmed, especially when they are not the experts for a move toward digital transformation. Therefore, it is crucial that organizations develop a strategic roadmap to facilitate the transition toward Industry 4.0. This study introduces such a roadmap in Figure 2 for Industry 4.0 adoption that can be used by manufacturing companies as a framework to transition from conventional to digital mode of manufacturing. It is to be noted that resistance to change is a widely reported phenomenon [180]; therefore, this roadmap was derived from existing and documented best practices within strategic management, marketing, management information system, supply chain management, and manufacturing technology management background. It is deeply rooted in the principles of lean six sigma [181] and follows the steps of design for six sigma (DFSS) [182]. It involves changing or redesigning the fundamental structure of a specific process or product and has 11 methodologies [183]. Some examples are DMADV (Define, Measure, Analyze, Design, Verify), CDDOV (Concept, Define, Design, Optimize, Verification), IDOV (Identify, Design, Optimize, Validate), and DMEDI (Define, Measure, Evaluate, Develop, Implement). The approach used here is an amalgamation called DMEODVI (Define, Measure, Evaluate, Optimize, Develop, Validate, Implement), to ensure the development of a structured and holistic approach. It is then followed up by DMAIC (Define, Measure, Analyze, Improve, Control), to apply continuous improvement after the transition. 
Table 1. Opportunities offered by Industry 4.0 enabling technologies.

\begin{tabular}{|c|c|c|c|}
\hline \multicolumn{2}{|c|}{ Industry 4.0 Enabling Technologies } & Opportunities & \multirow[t]{2}{*}{ Development of Strategies } \\
\hline 1 & Additive Manufacturing & $\begin{array}{l}\text { Design flexibility, reduced set-up and } \\
\text { tooling time, lightweight and } \\
\text { customized products, less waste, } \\
\text { effective for mass production of both } \\
\text { large-scale and small-scale structures }\end{array}$ & \\
\hline 2 & Augmented Reality & $\begin{array}{l}\text { Faster and smarter product } \\
\text { development and assembly, enhanced } \\
\text { operator performance, expert support } \\
\text { provision, effective machine } \\
\text { maintenance and quality assurance }\end{array}$ & \multirow{8}{*}{$\begin{array}{ll}\text { - } & \text { Smart manufacturing } \\
\text { - } & \text { Strategic management } \\
\text { - } & \text { Inforation management } \\
\text { - } & \text { IT maturity and governance } \\
\text { - } & \text { Smart } \\
& \text { supply-chain management } \\
\text { - } & \text { Cross-functional IT integration } \\
\text { - } & \text { Technology management } \\
\text { - } & \text { Marketing } \\
\text { - } & \text { IoT management } \\
\text { - } & \text { Human resources } \\
\text { - } & \text { Customer } \\
\text { - } & \text { Legal practices } \\
\text { - } & \text { Change management } \\
\text { - } & \text { Risk management } \\
\text { - } & \text { Project management }\end{array}$} \\
\hline 3 & Simulation & $\begin{array}{l}\text { Optimize product/process parameters, } \\
\text { reduced investment risk, waste } \\
\text { minimization, allows faster prototyping, } \\
\text { virtual analysis of complex scenarios }\end{array}$ & \\
\hline 4 & Autonomous Robots & $\begin{array}{l}\text { Increase efficiency and productivity, } \\
\text { reduce error and re-work, operator } \\
\text { safety, exponential learning by } \\
\text { collecting and analyzing machine data }\end{array}$ & \\
\hline 5 & $\begin{array}{l}\text { Industrial Internet of } \\
\text { Things }\end{array}$ & $\begin{array}{l}\text { Interconnected systems, production } \\
\text { visibility, better inventory management, } \\
\text { safe working environment, reduce } \\
\text { machine downtime, increase quality }\end{array}$ & \\
\hline 6 & Big Data Analytics & $\begin{array}{l}\text { Asset/supply chain optimization, } \\
\text { product design/quality, better future } \\
\text { forecasting and identification of trends, } \\
\text { higher customer satisfaction }\end{array}$ & \\
\hline 7 & Cloud Computing & $\begin{array}{l}\text { Low capital costs, flexibility of } \\
\text { operations, disaster recovery, automatic } \\
\text { software updates, increased } \\
\text { collaboration, freedom of operation, } \\
\text { data security, opportunities for } \\
\text { upskilling workforce }\end{array}$ & \\
\hline 8 & Cyber Security & $\begin{array}{l}\text { Protect data and reduce risk of hacking, } \\
\text { inspires customer confidence, increase } \\
\text { productivity, protect against spyware, } \\
\text { worms, and viruses }\end{array}$ & \\
\hline 9 & $\begin{array}{l}\text { Horizontal and Vertical } \\
\text { Integration }\end{array}$ & $\begin{array}{l}\text { Optimize supply chain, increase } \\
\text { differentiation from competition, high } \\
\text { productivity, superior product quality, } \\
\text { less waste, reduce set-up costs, errors, } \\
\text { and machine downtime }\end{array}$ & \\
\hline
\end{tabular}

The DMEODVI approach stems from the extensive literature review presented in Section 2. It is not merely a combination of different DFSS methodologies, but a well-informed theorization based on the effects of Industry 4.0 enabling technologies on the manufacturing sector. It is crucial for organizations to implement Industry 4.0 as a means of adding value to their business rather than follow a global trend [184]. Understanding the benefits and resource requirements of Industry 4.0 is paramount to strategizing its implementation. This aspect was shown in Table 1, where different strategies were defined based on the discussions in Section 2. It is obvious that Industry 4.0 implementation requires the involvement of every business process within an organization to maximize its benefits; therefore, the digital implementation team should comprise practitioners, and not only individuals in senior management. This will remedy one of the main barriers in widening of the theory-praxis gap [185] and gives more credence to the DMEODVI approach. Another aspect of consideration for this theoretical framework is the identification of inter-relationships to ensure that the micro-dynamics of manufacturing organizations can be realistically captured [186]. This can be achieved through collaborative theorizing that takes advantage of the experience of both the industrial practitioners 
and academics, to ensure practical outcomes [187]. It requires understanding Industry 4.0 enabling technologies, goals of the manufacturing organization, efficient management practices, and their cumulative effect on the workforce to effectively theorize this non-linear vision [188]. Measuring this inter-relationship through critical to quality attributes of the manufacturing organization will help in maximizing Industry 4.0 benefits. For example, employing IIoT to enhance the manufacturing system's productivity will only go so far if not accompanied by BDA, due to the generation of copious amounts of data that the current systems are incapable of processing. However, BDA requires sophisticated hardware that is expensive; therefore, $\mathrm{CC}$ is a good option, as it can lower equipment costs. Considering the collation, storage, and processing of such large datasets, it is advisable to invest in CS protocols to safeguard proprietary information. In this context, understanding the limitations of the organization will inform the appropriate Industry 4.0 enabling technology deployment to solve a problem or to increase productivity through effective data management. For example, repeated machine breakdowns can be minimized through attaching sensors, collating data through IIoT, and storage and processing of data through CC and BDA, to develop models leading to informed decision-making. Such opportunities should be evaluated for problem-solving and used as reference for brainstorming and generating ideas in line with the critical to quality attributes of the organization.

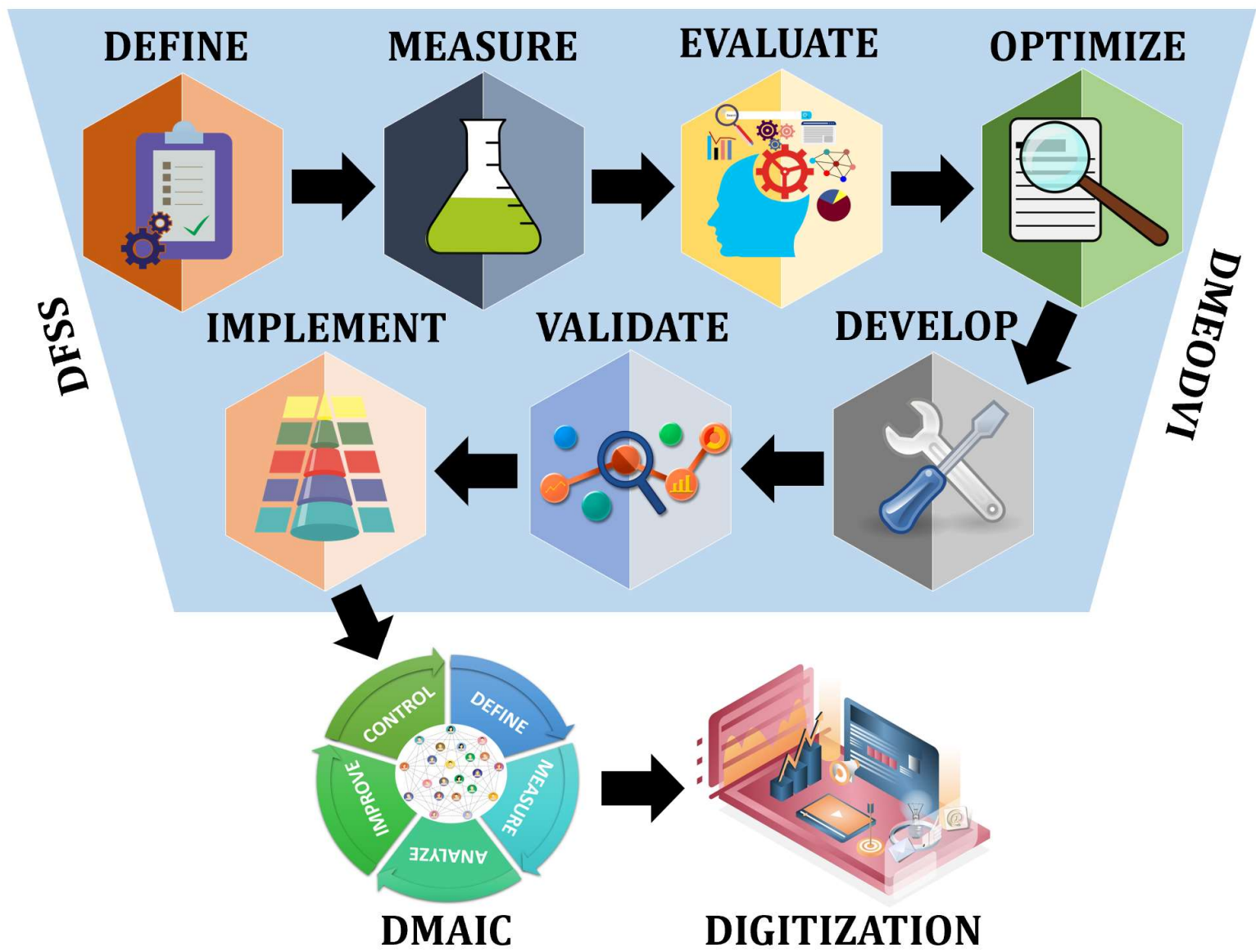

Figure 2. Strategic roadmap for Industry 4.0 implementation.

Theorizing ideas is an important part of practice [189] and can lead to innovations in problem-solving. Manufacturing organizations are quite adept at this due to the nature of their business, which requires continuous innovations in product design and process flows for better results. A pool of good ideas should lead to the identification of the best one that fits the organization's vision for the future. This idea should be optimized through useful principles familiar to the business, to ensure active involvement of the workforce rather than resistance to the new idea. The involvement of different epistemologies, especially related to lean and agile manufacturing [190], is encouraged, 
as such approaches can enhance the optimization process and can help in describing, as well as analyzing, concepts in different business settings [191]. Optimizing the pathways should logically lead to the development of the idea in a cost-effective manner. The manufacturing sector is well-aware of the intricacies of this phase, as it is a part and parcel of their core business. However, efforts for validating the developed idea/model requires a deep understanding of the underpinning strategies that govern the application of Industry 4.0 enabling technologies. The pilot testing should provide results that can increase confidence and can lead to the planning of full-scale pilot runs. At this stage, the digital transition plan should be reviewed to identify the role each piece of Industry 4.0 enabling technology is bound to play in achieving the organization's strategic goals. The full-scale implementation requires the support of the digital transition team to ensure optimized results that can match the requirements of the organization. From here onward, the operating procedures should be documented and standardized for use. It is good practice to employ continuous improvement protocols to enhance the manufacturing process, and the full-scale digital transformation will definitely benefit from this. Amid the conceptualization of the Industry 4.0 roadmap, special attention should be given to the workforce through all the phases, to ensure minimum resistance to change and active involvement, which can accelerate the process. The aspects presented in italics in this section are discussed in Section 4 as phases of the DMEODVI approach.

\section{Phases of the Strategic Industry 4.0 Roadmap}

In general, DFSS is associated with new services and product designs, whereas DMAIC is used on a product or process that already exists but is not conforming to customers' needs and/or specifications. The reason for choosing lean six sigma as a basis for this roadmap is that the manufacturing industry is familiar with these concepts and has been implementing them for decades. This will instigate a more favorable response from the workforce. Lean manufacturing methodologies have been deeply internalized in the culture of most industrial companies, since the 1990s. Typically, the program is modified slightly to fit the unique needs of a company's business model and processes. Today, nearly all large and mid-size manufacturers worldwide have a corporate business improvement program based on lean six sigma [192,193]. For sustained adoption, adding Industry 4.0 must occur in a way that aligns with the lean six sigma culture. The roadmap defined in Figure 2 is deeply rooted in established quality development and management systems widely used by the manufacturing industry. Issues arise with Industry 4.0 implementation when organizations are forced to embrace something completely new and they lose control over their own systems. The use of lean six sigma approaches is intended to mitigate that risk. The various phases of the strategic Industry 4.0 roadmap are explained in subsequent sections.

\subsection{First Phase: DEFINE}

As per the roadmap, the first phase is to DEFINE the business problem, identify the limitations of the existing resources, and develop a project scope for the implementation of Industry 4.0 technologies. This needs to involve both internal and external stakeholders, i.e., employees, management, shareholders, suppliers, and customers. An appropriate Industry 4.0 transition team should be assembled with individuals from all sectors of the business, to provide input. This will ensure one vision and uniformity of operations. The company and the Industry 4.0 transition team should decode the transition procedure into a detailed project plan and specify the characteristics of work in each phase of transition. This will help in identifying the functional needs and priorities, as well as the interand intra-organizational changes that are associated with each transitional phase. The manufacturing organization should also define its short-term, medium-term, and long-term Industry 4.0 strategies. This will help in developing SMART (Specific, Measurable, Attainable/Achievable, Realistic, Time-bound) objectives [194]. There is a need to evaluate the organization's current position, i.e., which Industry 4.0 technologies can be implemented and a plan for their implementation based on the business case. Manufacturers transitioning into Industry 4.0 need to devise new marketing strategies with 
an assessment of their level of digital market maturity [195]. The use of blockchain and BDA will allow predictive analysis of future market trends, as well as customer demands, and will also help in defining an appropriate customer strategy [196]. Therefore, a plan should be put in place to integrate these aspects.

In terms of defining strategies, the assessment of the existing workforce skillset and future training needs is the next step. Industry 4.0 will not be able to make a significant difference if it is opposed by the organization's existing workforce. Therefore, a change management strategy also needs to be defined, to allow a smooth transition from the traditional to the digital [197]. Industry 4.0 is characterized by the digitization of systems, and this will put the IT department under extreme stress. They need to be able to connect not only the production floor but develop a digital thread throughout the entire value chain [198]. The design principles and technology trends of Industry 4.0, such as horizontal and vertical integration, IIoT, CPS, interoperability, simulation, and blockchain, indicate that the fourth industrial revolution is all about IT. Therefore, it is crucial for manufacturing organizations to ensure that an IT governance team is in place to strategize, budget, execute, control, and report on IT advancement projects and operations, in accordance with the requirements of Industry 4.0 transition. With a plan in place for IT, smart manufacturing strategy can be easily defined, as well. It requires identification and subsequent incorporation of IIoT for establishing smart connections across the factory and vertical integration of machines, physical assets, databases, processes, and control systems, as well as the people who are interacting with them [199]. With a change in the manufacturing side, a defined strategy for supply-chain management is also required. Industry 4.0 has changed the supply-chain interactions due to the digitization aspect, and as it spreads more across the value chain, even the supply partners would need to integrate the digital twins of their operations with the aim of creating digital supply network, which significantly relies on IT alignment across value chain [200]. Legal practices will also be affected, and the establishment of smart contracts by using blockchain technology will become a norm [201]. Therefore, it is crucial to develop a legal strategy that can accommodate the new digital features of Industry 4.0. Along the lines of accommodation, manufacturing organizations need to ensure that a thorough risk-management strategy is in place for their digital transformation roadmap and there are mitigation actions in place to avoid losses [202]. This means that organizations should choose and plan the technologies that will give them the most benefit and should commit long-term to exploit the capabilities of Industry 4.0.

\subsection{Second Phase: MEASURE}

After defining the project, the MEASURE phase is used for data collation. The purpose of this phase is to clearly understand the customer's (internal and external) requirements and develop critical to process and quality attributes to address those requirements [203]. This is achieved by dividing the market into different segments, and then developing measurable critical to process and quality attributes for each segment using the quality function deployment (QFD) tool [204]. In the QFD tool, a house of quality is generated that captures the customer requirements and translates them into products or services [205]. For each identified critical to process and quality attribute, metrics and measurement systems are created. At this stage, it is critical to undertake a measurement system analysis (MSA) to ensure a realistic picture is captured. MSA is a thorough assessment of a measurement process, and it typically includes a specially designed experiment that seeks to identify the components of variation in that measurement process. The investigative elements in an MSA are bias, linearity, stability, repeatability, and reproducibility [206]. These can be measured by using statistical tools and control charts, such as run, pareto, cusum, and shewhart [207,208]. This is also helped by creating a value stream map, which is a popular lean manufacturing technique. It is a material and information-flow map used for analyzing the current state and designing a future state for the series of events that takes a product or service from the beginning of the specific process until it reaches the customer [209]. Organizations should perform a detailed cost-benefit analysis of different CTQs and their interdependency on each other. 


\subsection{Third Phase: EVALUATE}

The EVALUATE phase can take advantage of the already established Industry 4.0 readiness-assessment tools [210-213]. They are designed in a way to assess more than the technological burden and consider the wider implementation of Industry 4.0 by defining core dimensions (like the strategies presented in the DEFINE phase) and associated sub-dimensions. These tools can help to document and benchmark an organization's current level of Industry 4.0 readiness. In addition to benchmarking through the readiness-assessment tools, the critical to process and quality attributes can also be used for comparison with market leaders. After benchmarking, the project team can move toward generating alternative or new concept designs to accommodate the critical to process and quality attributes. These designs should consider the full breadth of the project scope, to ensure a truly digital transformation is achieved in the end. After arriving at the prioritized list of design features, the project team should list a few probable design concepts. The process experts and the $R \& D$ team should be involved in this process. It is necessary to brainstorm and use FMEA (failure mode and effects analysis) or a cause-and-effect diagram, etc., to facilitate the design process. Being innovative and creative will help the organization to remain competitive. However, it is also crucial to use established tools for reducing the number of possible designs. The team can make use of TRIZ (Russian terminology, known as theory of inventive problem-solving in English), which is a problem-solving, analysis, and forecasting tool. According to this tool, problems are similar across industries and countries and appear as unsolvable. However, a similar problem would have been solved somewhere in some other company/industry. Therefore, it is time-effective to convert a specific problem to a generic problem with a generic solution and then customize and apply this generic solution to the problem. TRIZ has a consolidated list of problems and their solutions readily available. This will reduce the time spent in R\&D and experimenting on a long list of possible options [214]. Another important tool is the Six Thinking Hats. It is a decision-evaluation tool that considers different aspects for evaluating a product or solution. Each aspect for evaluation is assigned a color. The team must evaluate the idea/product wearing each color hat. The colors are white (information and data), red (emotions), black (discernment), yellow (optimistic response), green (creativity), and blue (process). By doing this, the team will be able to identify all the pros and cons of the product/solution [215]. After generating some concepts for the new manufacturing process flow with the integrated Industry 4.0 technologies, an evaluation should take place to identify the optimal design, using the Pugh Matrix. It is an easy-to-use qualitative technique that can help in ranking the multidimensional options generated to identify the optimal option [216]. The purpose of the Pugh Matrix is to provide the project team with a holistic view of customer requirements against different alternatives in the form of a matrix, instead of listing the positives and negatives of each option. This helps in identifying the optimal option in a qualitative manner.

\subsection{Fourth Phase: OPTIMIZE}

The optimal design identified in the EVALUATE phase forms the basis for the OPTIMIZE phase. It is to be noted that the Pugh Matrix has only provided the optimal design based on the input parameters. A detailed design is built in this phase that can be subjected to numerical and statistical analysis to optimize its performance. Software packages for CAD design (e.g., Autodesk Inventor), process flow (e.g., AnyLogic), and product analysis (e.g., ANSYS) are employed. In addition, tools specific to the manufacturing industry can also be used to refine design parameters. Introducing the concept of lean management is important, as it helps in creating value to the customer by optimizing resources [217]. For example, evolutionary operations can introduce experimental designs and improvements while an ongoing full-scale manufacturing process continues to produce satisfactory results [218]. The design of experiments is a statistical technique for optimizing performance of systems with known input variables [219]. Another tool is the response surface methodology, which is a widely used mathematical and statistical method for modeling and analyzing a process in which the response of interest is affected by various variables, and the objective of this method is to optimize the 
response [220]. Optimized parameters based on these methodologies should be recorded and used for developing the new process integrating the technologies of Industry 4.0. The project team can also investigate conforming standards for technologies such as IIoT and cyber security, to ensure that they are moving in the right direction. This stage is crucial, and it is recommended that several optimization approaches are tested to ensure that every scenario and unexpected variation can be modeled before the test run.

\subsection{Fifth Phase: DEVELOP}

A detailed plan should be developed for the prototype build, based on the parameters identified in the previous phase. It is essential to involve more people at this stage, especially from the facilities management and IT departments, to ensure that both the hardware and software demands can be met in a reasonable manner. After acquiring all the necessary resources and skilled personnel, the next step is to identify the most economic method. Finally, the prototype manufacturing process flow should be developed according to the computer simulations, to ensure that they can be validated in the next phase. For a manufacturing process, this could mean setting up parallel production lines or using some machines for this prototype testing and others for the routine production. It is important to highlight that the Industry 4.0 implementation should not significantly disrupt the normal functionalities of the manufacturing organization and that the prototype should work in parallel to the day-to-day activities. The full-scale implementation is discussed in the seventh phase (Section 4.7).

\subsection{Sixth Phase: VALIDATE}

In this stage, the prototype is tested to validate the simulations from Section 4.4, depending upon the level of sophistication several pilot runs that could be conducted to ensure a seamless integration of all the defined strategies from Section 4.1. The reasons for running a pilot include lower risk of failure, assessing true performance in controlled-but-live experiments, confirming or disproving expected results and relationships, testing and validating the benefit of the proposed solutions before full-scale implementation, validating the measurement systems, identifying additional improvements in either the solution or implementation launch itself, improving future projections of benefits of full-scale implementation, increasing stake-holder buy-in, and quickly delivering a version of the solution to a targeted segment of the client population [221,222]. The pilot should be reversible and be planned in detail from the actual run. Like the DEFINE phase, the pilot run plan should entail clear goals, scope, timeline, activities list, personnel involved and their training needs, budgeting and resourcing, monitoring plan and operational definitions of measurements, methods of measurement, and data collation. During the run, the pilot should be exposed to a broad range of inputs and process conditions. After the pilot run, the project team should analyze the differences between the predicted performance and the actual performance. They should identify root causes for the differences and determine if changes are required. It is important to highlight that there will always be some difference between the simulated results and experimental results. The project team should review the existing literature to identify that acceptable difference range to make informed decisions.

The next step after the pilot run should be the communication of results through different means and soliciting stakeholder feedback on the outcomes. Change management is a key part of project success, and soliciting feedback during stakeholder interviews gives insight to the opinions of those impacted by the project [223]. The team should review the original stakeholder analysis to determine how/if anything has changed, and what can be done to address those results. The results of the pilot run should also be compared to the scope and goals of the project (Section 4.1). It is common for projects to overrun their baseline schedule and budgets. Therefore, it is crucial to be objective in the assessment of the pilot runs and not show bias either in favor or against, as that might hide the real results of the pilot run [224]. If the results are objectively assessed as unfavorable for the organization, then the project team needs to evaluate their performance and make use of their own risk management strategy, to identify and mitigate the issues. In the case of the results being favorable, the project team 
needs to discuss plans for scaling-up the design. This would require again going through phases three, four, and five, to ensure the optimal solution is being employed in the organization. The team should also develop a transition implementation plan and document the operating procedures of the pilot run(s).

\subsection{Seventh Phase: IMPLEMENT}

The successful validation of the prototype manufacturing process should lead to full-scale implementation. In this phase, a full-scale pilot is conducted. The pilot is a permanent deployment that delivers fully on the control plans to monitor the activities involved in the new process. This phase should be conducted in the same manner as the pilot run but should be adjusted to accommodate the results of the pilot run. The focus should be on cost savings, as it is one of the features of the six sigma approach. Prioritization matrices can be used to rationally narrow down the focus of the team before detailed implementation planning can take place. The barriers to implementation will again be associated with resistance to change [225], and it is more crucial than in any of the phases before to manage change and support the workforce toward this digital transition. It is a good idea to establish a 'steering board for digital implementation' by involving more senior management personnel to take advantage of their experience. Furthermore, personnel from the original project team should be trained to become 'digital champions' who can take this initiative forward and create a sense of ownership among the workforce [226].

The pilot plan should be adjusted for any problems or learnings that occurred during the pilot run and for the difference in the scale of the rollout. The project team should identify factors favoring/opposing the implementation and recognize implications, as well as risks, from failing to address the barriers. Once the process design has been finalized, the implementation should take place. After the successful implementation of the new process, data should be gathered, and the matrices should be compared with the DEFINE phase, to ensure that the project yielded the required results for the organization. The operating procedures should be documented and standardized for use. A plan should be developed by the steering board for digital implementation and digital champions that should include large-scale training needs for new work methods and approaches of fine-tuning the new process [227].

Once the system is up and running, then the goal is to continuously improve quality by monitoring, reviewing, and implementing appropriate changes, but on a small-scale and for a specific area. For this purpose, DMAIC (Define, Measure, Analyze, Improve, Control) is a good approach, as it takes less time than DFSS to implement. The first three tasks of DMAIC are like the first three phases of DMEODVI, and the last two deal with improving a specific aspect and controlling the output, respectively. It is common practice to introduce Kaizen teams for DMAIC. The team could be led by an external Kaizen expert, and the team can comprise individuals from the steering board for digital implementation and the pool of digital champions. Kaizen teams are an essential part of any project because they can help guide the organization through a specific event, while also working to maintain progress in between events $[228,229]$. Members of a Kaizen team should be encouraged to continue to develop their knowledge of the Kaizen strategies and help in any way they can with all Kaizen events. These events or projects (such as the process of continuous improvement using DMAIC) are typically chosen to be short in terms of how long they take to implement, but they should also address one specific area completely [230]. These types of events require planning and training to be provided to everyone who is involved in the project, and that is often where the Kaizen teams can be most effective. Having such training sessions would be extremely beneficial for the Kaizen teams, to the point that they would not require an external expert for future projects. This integrated roadmap comprising DFSS and DMAIC can form the basis for manufacturing organizations in implementing Industry 4.0 initiatives with familiar approaches to accelerate its adoption and limit their resistance to change. The next stage would be the validation of this methodology by implementing Industry 4.0 enabling technologies in a manufacturing organization. 


\section{Conclusions}

Industry 4.0 has revolutionized the manufacturing industry. However, there are still major challenges associated with not only its adoption but its implementation as well. The practical contributions of this paper are twofold. Firstly, it provides a state-of-the-art literature review of Industry 4.0 enabling technologies and their impact on the manufacturing industry. Secondly, it presents a strategic roadmap for Industry 4.0 implementation that is suitable for manufacturers, by utilizing the lean six sigma principles. This roadmap can provide a basic framework to manufacturing organizations in their transitional journey toward the implementation of Industry 4.0. The use of lean six sigma also limits the risk of failure factors (e.g., cultural, structural, and strategic), as manufactures have been employing these strategies for decades and will be less resistant to their use albeit for a different type of implementation. With the growing support from government bodies encouraging the uptake of Industry 4.0, manufacturing organizations need to take advantage and transition into truly digital manufacturing enterprises that can benefit the economy and build a sustainable ecosystem for manufacturing.

Funding: This research received no external funding.

Conflicts of Interest: There is only one author; hence, there is no conflict of interest.

\section{References}

1. Popkova, E.G.; Ragulina, Y.V.; Bogoviz, A.V. Fundamental differences of transition to industry 4.0 from previous industrial revolutions. In Industry 4.0: Industrial Revolution of the 21st Century; Springer: Cham, Swizerland, 2019; pp. 21-29.

2. Kagermann, H.; Helbig, J.; Hellinger, A.; Wahlster, W. Recommendations for Implementing the Strategic Initiative INDUSTRIE 4.0: Securing the Future of German Manufacturing Industry; Final Report of the Industrie 4.0 Working Group; Forschungsunion: Germany, 2013.

3. Lasi, H.; Fettke, P.; Kemper, H.G.; Feld, T.; Hoffmann, M. Industry 4.0. Bus. Inform. Syst. Eng. 2014, 6, 239-242. [CrossRef]

4. Lu, Y. Industry 4.0: A survey on technologies, applications and open research issues. J. Ind. Inform. Integr. 2017, 6, 1-10. [CrossRef]

5. Lee, J.; Kao, H.A.; Yang, S. Service innovation and smart analytics for industry 4.0 and big data environment. Procedia Cirp 2014, 16, 3-8. [CrossRef]

6. Gorecky, D.; Schmitt, M.; Loskyll, M.; Zühlke, D. Human-machine-interaction in the industry 4.0 era. In Proceedings of the 2014 12th IEEE international conference on industrial informatics (INDIN), Porto Alegre, RS, Brazil, 27-30 July 2014; IEEE: Piscataway, NJ, USA, 2014; pp. 289-294.

7. Kiel, D.; Müller, J.M.; Arnold, C.; Voigt, K.I. Sustainable industrial value creation: Benefits and challenges of industry 4.0. Int. J. Innov. Manag. 2017, 21, 1740015. [CrossRef]

8. Available online: https://slcontrols.com/benefits-of-industry-4--0/ (accessed on 10 April 2020).

9. Industry 4.0. Available online: https://ec.europa.eu/growth/tools-databases/dem/monitor/tags/industry-40 (accessed on 10 April 2020).

10. What does the Fourth Industrial Revolution (4IR) Mean for UK Business? Available online: https://innovateuk .blog.gov.uk/2017/03/28/what-does-the-fourth-industrial-revolution-4ir-mean-for-uk-business/ (accessed on 10 April 2020).

11. Urciuoli, L.; Hintsa, J.; Ahokas, J. Drivers and barriers affecting usage of e-Customs-A global survey with customs administrations using multivariate analysis techniques. Gov. Inform. Quart. 2013, 30, 473-485. [CrossRef]

12. Müller, J.M.; Däschle, S. Business model innovation of industry 4.0 solution providers towards customer process innovation. Processes 2018, 6, 260. [CrossRef]

13. Zhu, Q.; Geng, Y. Drivers and barriers of extended supply chain practices for energy saving and emission reduction among Chinese manufacturers. J. Clean. Prod. 2013, 40, 6-12. [CrossRef]

14. About the GrowIn 4.0 Project. Available online: https://northsearegion.eu/growin4/about-the-growin-40-pr oject/ (accessed on 10 April 2020). 
15. Industry 4.0. Available online: https://www.industry.gov.au/funding-and-incentives/industry-40 (accessed on 10 April 2020).

16. Hermann, M.; Pentek, T.; Otto, B. January. Design principles for industrie 4.0 scenarios. In Proceedings of the 2016 49th Hawaii international conference on system sciences (HICSS), Koloa, HI, USA, 5-8 January 2016; IEEE: Piscataway, NJ, USA, 2016; pp. 3928-3937.

17. Industry 4.0 Design Principles. Available online: https://www.rmit.edu.au/industry/develop-your-workforc e/tailored-workforce-solutions/c4de/articles/industry-40-design-principles (accessed on 10 April 2020).

18. Luthra, S.; Mangla, S.K. Evaluating challenges to Industry 4.0 initiatives for supply chain sustainability in emerging economies. Process. Saf. Environ. Prot. 2018, 117, 168-179. [CrossRef]

19. Available online: https://www.infopulse.com/blog/the-main-benefits-and-challenges-of-industry-4--0-adop tion-in-manufacturing/ (accessed on 10 April 2020).

20. Sarvari, P.A.; Ustundag, A.; Cevikcan, E.; Kaya, I.; Cebi, S. Technology roadmap for Industry 4.0. In Industry 4.0: Managing the Digital Transformation; Springer: Cham, Swizerland, 2018; pp. 95-103.

21. Ghobakhloo, M. The future of manufacturing industry: A strategic roadmap toward Industry 4.0. J. Manuf. Technol. Manag. 2018, 29, 910-936. [CrossRef]

22. Pessl, E.; Sorko, S.R.; Mayer, B. Roadmap Industry 4.0-implementation guideline for enterprises. Int. J. Sci. Technol. Soc. 2017, 5, 193-202. [CrossRef]

23. Colli, M.; Madsen, O.; Berger, U.; Møller, C.; Wæhrens, B.V.; Bockholt, M. Contextualizing the outcome of a maturity assessment for Industry 4.0. Ifac-papersonline 2018, 51, 1347-1352. [CrossRef]

24. Ivanov, D.; Dolgui, A.; Sokolov, B.; Werner, F.; Ivanova, M. A dynamic model and an algorithm for short-term supply chain scheduling in the smart factory industry 4.0. Int. J. Prod. Res. 2016, 54, 386-402. [CrossRef]

25. Butt, J. A Novel Additive Manufacturing Process for the Production of Metal Parts. Ph.D. Thesis, Anglia Ruskin University, Cambridge, UK, 2016.

26. Butt, J.; Shirvani, H. Additive, subtractive, and hybrid manufacturing processes. In Advances in Manufacturing and Processing of Materials and Structures; CRC Press: Boca Raton, FL, USA, 2018; pp. 187-218.

27. ISO. ISO ASTM52900-15, Standard Terminology for Additive Manufacturing-General Principles-Terminology; ASTM International: West Conshohocken, PA, USA, 2015; Available online: www.astm.org (accessed on 10 April 2020).

28. Ko, H.; Moon, S.K.; Hwang, J. Design for additive manufacturing in customized products. Int. J. Precis. Eng. Manuf. 2015, 16, 2369-2375. [CrossRef]

29. Butt, J.; Mebrahtu, H.; Shirvani, H. Strength analysis of aluminium foil parts made by composite metal foil manufacturing. Prog. Addit. Manuf. 2016, 1, 93-103. [CrossRef]

30. Butt, J.; Onimowo, D.A.; Gohrabian, M.; Sharma, T.; Shirvani, H. A desktop 3D printer with dual extruders to produce customised electronic circuitry. Front. Mech. Eng. 2018, 13, 528-534. [CrossRef]

31. Gao, J. August. Production of Multiple Material Parts Using a Desktop 3D Printer. In Advances in Manufacturing Techno, XXXI: Proceedings of the 15th International Conference on Manufacturing Research, Incorporating the 32nd National Conference on Manufacturing Research, University of Greenwich, London, UK, 5-7 September 2017; IOS Press: Amsterdam, The Netherlands, 2017; Volume 6, p. 148.

32. Butt, J.; Hewavidana, Y.; Mohaghegh, V.; Sadeghi-Esfahlani, S.; Shirvani, H. Hybrid Manufacturing and Experimental Testing of Glass Fiber Enhanced Thermoplastic Composites. J. Manuf. Mater. Process. 2019, 3, 96. [CrossRef]

33. Seifi, M.; Gorelik, M.; Waller, J.; Hrabe, N.; Shamsaei, N.; Daniewicz, S.; Lewandowski, J.J. Progress towards metal additive manufacturing standardization to support qualification and certification. Jom 2017, 69, 439-455. [CrossRef]

34. Butt, J.; Mebrahtu, H.; Shirvani, H. Microstructure and mechanical properties of dissimilar pure copper foil/1050 aluminium composites made with composite metal foil manufacturing. J. Mater. Process. Technol. 2016, 238, 96-107. [CrossRef]

35. Butt, J.; Ghorabian, M.; Mohaghegh, V.; Shirvani, H. Finite Element Modeling and Mechanical Testing of Metal Composites Made by Composite Metal Foil Manufacturing. J. Manuf. Mater. Process. 2019, 3, 81. [CrossRef]

36. Butt, J.; Shirvani, H. Experimental analysis of metal/plastic composites made by a new hybrid method. Addit. Manuf. 2018, 22, 216-222. [CrossRef] 
37. Yakout, M.; Cadamuro, A.; Elbestawi, M.A.; Veldhuis, S.C. The selection of process parameters in additive manufacturing for aerospace alloys. Int. J. Adv. Manuf. Technol. 2017, 92, 2081-2098. [CrossRef]

38. Böckin, D.; Tillman, A.M. Environmental assessment of additive manufacturing in the automotive industry. J. Clean. Prod. 2019, 226, 977-987. [CrossRef]

39. Khoshnevis, B.; Hwang, D.; Yao, K.T.; Yeh, Z. Mega-scale fabrication by contour crafting. Int. J. Ind. Syst. Eng. 2006, 1, 301-320. [CrossRef]

40. Available online: https://www.branch.technology/ (accessed on 2 April 2020).

41. Available online: https://d-shape.com/ (accessed on 2 April 2020).

42. Bos, F.; Wolfs, R.; Ahmed, Z.; Salet, T. Additive manufacturing of concrete in construction: Potentials and challenges of 3D concrete printing. Virtual Phys. Prototyp. 2016, 11, 209-225. [CrossRef]

43. Keating, S.J.; Leland, J.C.; Cai, L.; Oxman, N. Toward site-specific and self-sufficient robotic fabrication on architectural scales. Sci. Robot. 2017, 2, eaam8986. [CrossRef]

44. World's 1st 3D Printed Neighborhood Being Built in Mexico. Available online: https://www.wbur.org/herea ndnow/2020/02/06/worlds-first-3d-printed-neighborhood-mexico (accessed on 2 April 2020).

45. WinSun deploys 3D Printed Isolation Wards for Coronavirus Medical Staff. Available online: https://www. 3dprintingmedia.network/winsun-3d-printed-isolation-wards-coronavirus-medical-workers/ (accessed on 2 April 2020).

46. Popovich, A.; Sufiiarov, V.; Polozov, I.; Borisov, E.; Masaylo, D. Producing hip implants of titanium alloys by additive manufacturing. Int. J. Biopr. 2016, 2, 78-84. [CrossRef]

47. 3D Printing Community Responds to COVID-19 and Coronavirus Resources. Available online: https://3dprintingindustry.com/news/3d-printing-community-responds-to-covid-19-and-coronav irus-resources-169143/ (accessed on 3 April 2020).

48. Gattullo, M.; Uva, A.E.; Fiorentino, M.; Gabbard, J.L. Legibility in industrial AR: Text style, color coding, and illuminance. IEEE Comput. Graph. Appl. 2015, 35, 52-61. [CrossRef]

49. Ceruti, A.; Marzocca, P.; Liverani, A.; Bil, C. Maintenance in aeronautics in an Industry 4.0 context: The role of Augmented Reality and Additive Manufacturing. J. Comput. Des. Eng. 2019, 6, 516-526. [CrossRef]

50. Mujber, T.S.; Szecsi, T.; Hashmi, M.S. Virtual reality applications in manufacturing process simulation. J. Mater. Process. Technol. 2004, 155, 1834-1838. [CrossRef]

51. Gracia, L.; Perez-Vidal, C.; Mronga, D.; de Paco, J.M.; Azorin, J.M.; de Gea, J. Robotic manipulation for the shoe-packaging process. Int. J. Adv. Manuf. Technol. 2017, 92, 1053-1067. [CrossRef]

52. Gervautz, M.; Schmalstieg, D. Anywhere interfaces using handheld augmented reality. Computer 2012, 45, 26-31. [CrossRef]

53. Chi, H.L.; Kang, S.C.; Wang, X. Research trends and opportunities of augmented reality applications in architecture, engineering, and construction. Autom. Constr. 2013, 33, 116-122. [CrossRef]

54. Zhou, F.; Duh, H.B.L.; Billinghurst, M. Trends in augmented reality tracking, interaction and display: A review of ten years of ISMAR. In Proceedings of the 2008 7th IEEE/ACM International Symposium on Mixed and Augmented Reality, Cambridge, UK, 15-18 September 2008; IEEE: Piscataway, NJ, USA, 2008; pp. 193-202.

55. Piumsomboon, T.; Altimira, D.; Kim, H.; Clark, A.; Lee, G.; Billinghurst, M. Grasp-Shell vs gesture-speech: A comparison of direct and indirect natural interaction techniques in augmented reality. In Proceedings of the 2014 IEEE International Symposium on Mixed and Augmented Reality (ISMAR), Munich, Germany, 10-12 September 2014; IEEE: Piscataway, NJ, USA, 2014; pp. 73-82.

56. Nee, A.Y.; Ong, S.K.; Chryssolouris, G.; Mourtzis, D. Augmented reality applications in design and manufacturing. CIRP Ann. 2012, 61, 657-679. [CrossRef]

57. Akçayır, M.; Akçayır, G. Advantages and challenges associated with augmented reality for education: A systematic review of the literature. Educational Research Review 2017, 20,1-11. [CrossRef]

58. Posada, J.; Zorrilla, M.; Dominguez, A.; Simoes, B.; Eisert, P.; Stricker, D.; Rambach, J.; Döllner, J.; Guevara, M. Graphics and media technologies for operators in industry 4.0. IEEE Comput. Graph. Appl. 2018, 38, 119-132. [CrossRef] [PubMed]

59. Segura, Á.; Diez, H.V.; Barandiaran, I.; Arbelaiz, A.; Álvarez, H.; Simões, B.; Posada, J.; García-Alonso, A.; Ugarte, R. Visual computing technologies to support the Operator 4.0. Comput. Ind. Eng. 2018, 105550. [CrossRef] 
60. Makris, S.; Pintzos, G.; Rentzos, L.; Chryssolouris, G. Assembly support using AR technology based on automatic sequence generation. CIRP Ann. 2013, 62, 9-12. [CrossRef]

61. Uva, A.E.; Gattullo, M.; Manghisi, V.M.; Spagnulo, D.; Cascella, G.L.; Fiorentino, M. Evaluating the effectiveness of spatial augmented reality in smart manufacturing: A solution for manual working stations. Int. J. Adv. Manuf. Technol. 2018, 94, 509-521. [CrossRef]

62. Molineros, J.; Sharma, R. Computer vision for guiding manual assembly. In Proceedings of the 2001 IEEE International Symposium on Assembly and Task Planning (ISATP2001). Assembly and Disassembly in the Twenty-First Century, Fukuoka, Japan, 28-30 May 2001; (Cat. No. 01TH8560). IEEE: Piscataway, NJ, USA, 2001; pp. 362-368.

63. Doshi, A.; Smith, R.T.; Thomas, B.H.; Bouras, C. Use of projector based augmented reality to improve manual spot-welding precision and accuracy for automotive manufacturing. Int. J. Adv. Manuf. Technol. 2017, 89, 1279-1293. [CrossRef]

64. Zhou, J.; Lee, I.; Thomas, B.; Menassa, R.; Farrant, A.; Sansome, A. In-situ support for automotive manufacturing using spatial augmented reality. Int. J. Virtual Real. 2012, 11, 33-41. [CrossRef]

65. Zhu, Z.; Liu, C.; Xu, X. Visualisation of the Digital Twin data in manufacturing by using Augmented Reality. Procedia CIRP 2019, 81, 898-903. [CrossRef]

66. Lee, H. Real-time manufacturing modeling and simulation framework using augmented reality and stochastic network analysis. Virtual Real. 2019, 23, 85-99. [CrossRef]

67. Blaga, A.; Tamas, L. Augmented Reality for Digital Manufacturing. In Proceedings of the 2018 26th Mediterranean Conference on Control and Automation (MED), Zadar, Croatia, 19-22 June 2018; IEEE: Piscataway, NJ, USA, 2018; pp. 173-178.

68. Guala, F. Models, simulations, and experiments. In Model-Based Reasoning; Springer: Boston, MA, USA, 2002; pp. 59-74.

69. Ngaile, G.; Altan, T. Simulations of manufacturing processes: Past, present, and future. Adv. Technol. Plast. 2002, 1, 271-282.

70. Wörner, M.; Ertl, T.; Miksch, S.; Santucci, G. Visual analysis of advanced manufacturing simulations. In Proceedings of the EuroVa 2011: International Workshop on Visual Analytics, Bergen, Norway, 31 May 2011; pp. 29-32.

71. Acheson, C.; Mackle, D.; Murphy, A.; Butterfield, J.; Higgins, P.; Collins, R.; Tame, R. Using design of experiments to define factory simulations for manufacturing investment decisions. In Proceedings of the 34th International Manufacturing Conference, Sligo, Ireland, 30-31 August 2017.

72. Ruediger, P.; Hagen, H. Dealing with uncertainties in manufacturing process simulations. In Applied Mechanics and Materials; Trans Tech Publications Ltd.: Stafa-Zurich, Switzerland, 2017; Volume 869, pp. 226-233.

73. Al-Tamimi, A.A.; Quental, C.; Folgado, J.; Peach, C.; Bartolo, P. Stress analysis in a bone fracture fixed with topology-optimised plates. Biomech. Model. Mechanobiol. 2019, 19, 693-699. [CrossRef]

74. Grivc, U.; Deržič, D.; Muhič, S. Numerical optimisation and experimental validation of divided rail freight brake disc crown. J. Mod. Transp. 2019, 27, 1-10. [CrossRef]

75. Migliaccio, M.; Montanaro, A.; Beatrice, C.; Napolitano, P.; Allocca, L.; Fraioli, V. Experimental and numerical analysis of a high-pressure outwardly opening hollow cone spray injector for automotive engines. Fuel 2017, 196, 508-519. [CrossRef]

76. Khan, M.A.A.; Butt, J.; Mebrahtu, H.; Shirvani, H.; Alam, M.N. Data-Driven Process Reengineering and Optimization Using a Simulation and Verification Technique. Designs 2018, 2, 42. [CrossRef]

77. Khan, M.A.A.; Butt, J.; Mebrahtu, H.; Shirvani, H.; Sanaei, A.; Alam, M.N. Integration of Data-Driven Process Re-Engineering and Process Interdependence for Manufacturing Optimization Supported by Smart Structured Data. Designs 2019, 3, 44. [CrossRef]

78. Stadnicka, D.; Antonelli, D. Application of value stream mapping and possibilities of manufacturing processes simulations in automotive. FME Trans. 2015, 43, 279-286. [CrossRef]

79. Avventuroso, G.; Silvestri, M.; Frazzon, E.M. Additive manufacturing plant for large scale production of medical devices: A simulation study. IFAC-PapersOnLine 2018, 51, 1442-1447. [CrossRef]

80. Bekey, G.A. Autonomous Robots: From Biological Inspiration to Implementation and Control; MIT Press: Cambridge, MA, USA, 2005.

81. Engelberger, J.F. Robot in Practice: Manag. and Applications of Industrial Robots; Springer Science \& Business Media: Berlin/Heidelberg, Germany, 2012. 
82. Djuric, A.M.; Urbanic, R.J.; Rickli, J.L. A framework for collaborative robot (CoBot) integration in advanced manufacturing systems. SAE Int. J. Mater. Manuf. 2016, 9, 457-464. [CrossRef]

83. A Positioning Paper by the International Federation of Robotics. Available online: https://ifr.org/downloads/ papers/IFR_Demystifying_Collaborative_Robots.pdf (accessed on 3 April 2020).

84. International Organization for Standardization. ISO/TS 15066: 2016 Robots and Robotic Devices-Collaborative Robots; International Organization for Standardization: Geneva, Switzerland, 2016.

85. ISO. ISO 10218-1:2011 Robots and Robotic Devices—Safety Requirements for Industrial Robots_Part 1: Robots; International Organization for Standardization: Geneva, Switzerland, 2011.

86. ISO. ISO 10218-2: 2011: Robots and Robotic Devices-Safety Requirements for Industrial Robots-Part 2: Robot Systems and Integration; International Organization for Standardization: Geneva, Switzerland, 2011.

87. Fast-Berglund, Å.; Palmkvist, F.; Nyqvist, P.; Ekered, S.; Åkerman, M. Evaluating cobots for final assembly. Procedia CIRP 2016, 44, 175-180. [CrossRef]

88. Cherubini, A.; Passama, R.; Crosnier, A.; Lasnier, A.; Fraisse, P. Collaborative manufacturing with physical human-robot interaction. Robot. Comput.-Integr. Manuf. 2016, 40, 1-13. [CrossRef]

89. Sadik, A.R.; Urban, B. An ontology-based approach to enable knowledge representation and reasoning in worker-cobot agile manufacturing. Future Internet 2017, 9, 90. [CrossRef]

90. Meziane, R.; Otis, M.J.D.; Ezzaidi, H. Human-robot collaboration while sharing production activities in dynamic environment: SPADER system. Robot. Comput.-Integr. Manuf. 2017, 48, 243-253. [CrossRef]

91. Kildal, J.; Tellaeche, A.; Fernández, I.; Maurtua, I. Potential users' key concerns and expectations for the adoption of cobots. Procedia CIRP 2018, 72, 21-26. [CrossRef]

92. Mariscal, M.A.; González-Pérez, J.; Khalid, A.; Gutierrez-Llorente, J.M.; García-Herrero, S. Risks management and cobots. Identifying critical variables. Safety 2011, 10218, 2.

93. Xiong, H.; Mei, Q.; Zhao, Y. Efficient and provably secure certificateless parallel key-insulated signature without pairing for IIoT environments. IEEE Syst. J. 2019. [CrossRef]

94. The Internet of Things in Manufacturing: Benefits, Use Cases and Trends. Available online: https://www.i-scoo p.eu/internet-of-things-guide/internet-of-things-in-manufacturing/ (accessed on 4 April 2020).

95. Seven Things You Need To Know About IIoT in Manufacturing. Available online: https://www.forbes.com/sites/lou iscolumbus/2019/06/02/seven-things-you-need-to-know-about-iiot-in-manufacturing_updated/\#180b80db5f56 (accessed on 4 April 2020).

96. Schneider, S. The industrial internet of things (iiot) applications and taxonomy. Internet Things Data Anal. Handb. 2017, 41-81. [CrossRef]

97. Rose, K.; Eldridge, S.; Chapin, L. The Internet of Things: An Overview; The Internet Society (ISOC): Reston, VA, USA, 2015; Volume 80.

98. Boyes, H.; Hallaq, B.; Cunningham, J.; Watson, T. The industrial internet of things (IIoT): An analysis framework. Comput. Ind. 2018, 101, 1-12. [CrossRef]

99. IoT in Manufacturing: The Ultimate Guide. Available online: https://www.scnsoft.com/blog/iot-in-manufact uring\#Adoption_drivers (accessed on 4 April 2020).

100. Lee, J.; Bagheri, B.; Kao, H.A. A cyber-physical systems architecture for industry 4.0-based manufacturing systems. Manuf. Lett. 2015, 3, 18-23. [CrossRef]

101. Monostori, L.; Kádár, B.; Bauernhansl, T.; Kondoh, S.; Kumara, S.; Reinhart, G.; Sauer, O.; Schuh, G.; Sihn, W.; Ueda, K. Cyber-physical systems in manufacturing. Cirp Ann. 2016, 65, 621-641. [CrossRef]

102. Tao, F.; Cheng, J.; Qi, Q.; Zhang, M.; Zhang, H.; Sui, F. Digital twin-driven product design, manufacturing and service with big data. Int. J. Adv. Manuf. Technol. 2018, 94, 3563-3576. [CrossRef]

103. Grieves, M.; Vickers, J. Digital twin: Mitigating unpredictable, undesirable emergent behavior in complex systems. In Transdisciplinary Perspectives on Complex Systems; Springer: Cham, Swizerland, 2017; pp. 85-113.

104. Sisinni, E.; Saifullah, A.; Han, S.; Jennehag, U.; Gidlund, M. Industrial internet of things: Challenges, opportunities, and directions. IEEE Trans. Ind. Inform. 2018, 14, 4724-4734. [CrossRef]

105. Kiel, D.; Arnold, C.; and Voigt, K.I. The influence of the Industrial Internet of Things on business models of established manufacturing companies-A business level perspective. Technovation 2017, 68, 4-19. [CrossRef]

106. Gierej, S. The framework of business model in the context of Industrial Internet of Things. Procedia Eng. 2017, 182, 206-212. [CrossRef]

107. Yerra, V.A.; Pilla, S. IIoT-Enabled Production System for Composite Intensive Vehicle Manufacturing. SAE Int. J. Eng. 2017, 10, 209-214. [CrossRef] 
108. Vita, R.; Caldas, N.; Basto, J.; Alcalá, S.; Diniz, F. An IIoT-based architecture for decision support in the aeronautic industry. In MATEC Web of Conferences; EDP Sciences: Les Ulis, French, 2019; Volume 304, p. 04004.

109. Arnold, C.; and Voigt, K.I. Ecosystem Effects of the Industrial Internet of Things on Manufacturing Companies. Acta Infol. 2017, 1, 99-108.

110. Seetharaman, A.; Patwa, N.; Saravanan, A.S.; Sharma, A. Customer expectation from industrial internet of things (IIOT). J. Manuf. Technol. Manag. 2019, 30, 1161-1178. [CrossRef]

111. Balaji, V.; Venkumar, P.; Sabitha, M.S.; Amuthaguka, D. DVSMS: Dynamic value stream mapping solution by applying IIoT. Sādhanā 2020, 45, 38. [CrossRef]

112. Available online: https://www.iiconsortium.org/ (accessed on 4 April 2020).

113. Zhang, Y.; Ren, S.; Liu, Y.; Si, S. A big data analytics architecture for cleaner manufacturing and maintenance processes of complex products. J. Clean. Prod. 2017, 142, 626-641. [CrossRef]

114. Beyer, M.A.; Laney, D. The importance of 'big data': A definition. Stamford CT Gart. 2012, 21, 2014-2018.

115. Tewari, S.; Dwivedi, U.D. Ensemble-based big data analytics of lithofacies for automatic development of petroleum reservoirs. Comput. Ind. Eng. 2019, 128, 937-947. [CrossRef]

116. The 42 V's of Big Data and Data Science. Available online: https://www.elderresearch.com/blog/42-v-of-big -data (accessed on 4 April 2020).

117. Gandomi, A.; Haider, M. Beyond the hype: Big data concepts, methods, and analytics. Int. J. Inform. Manag. 2015, 35, 137-144. [CrossRef]

118. Toro, C.; Barandiaran, I.; Posada, J. A perspective on Knowledge Based and Intelligent systems implementation in Industrie 4.0. Procedia Comput. Sci. 2015, 60, 362-370. [CrossRef]

119. Toro, C.; Vaquero, J.; Graña, M.; Sanín, C.; Szczerbicki, E.; Posada, J. Building domain ontologies from engineering standards. Cybern. Syst. 2012, 43, 114-126. [CrossRef]

120. Belhadi, A.; Zkik, K.; Cherrafi, A.; Yusof, M. Understanding the capabilities of Big Data Analytics for manufacturing process: Insights from literature review and multiple case study. Comput. Ind. Eng. 2019, 106099. [CrossRef]

121. Joseph, R.C.; Johnson, N.A. Big data and transformational government. It Prof. 2013, 15, 43-48. [CrossRef]

122. Banerjee, A.; Bandyopadhyay, T.; Acharya, P. Data analytics: Hyped up aspirations or true potential? Vikalpa 2013, 38, 1-12. [CrossRef]

123. Cheng, Y.; Chen, K.; Sun, H.; Zhang, Y.; Tao, F. Data and knowledge mining with big data towards smart production. J. Ind. Inform. Integr. 2018, 9, 1-13. [CrossRef]

124. Raghupathi, W.; Raghupathi, V. Big data analytics in healthcare: Promise and potential. Health Inform. Sci. Syst. 2014, 2, 3. [CrossRef] [PubMed]

125. Nedelcu, B. About big data and its challenges and benefits in manufacturing. Database Syst. J. 2013, 4, 10-19.

126. Big Data Analytics in Manufacturing Industry Set to Exceed $\$ 4.5$ Billion by 2025 -Condition Monitoring to Register Significant Growth. Available online: https://www.prnewswire.com/news-releases/big-data-analyt ics-in-manufacturing-industry-set-to-exceed-4-5-billion-by-2025---condition-monitoring-to-register-sig nificant-growth-301033518.html (accessed on 4 April 2020).

127. Zhong, R.Y.; Xu, C.; Chen, C.; and Huang, G.Q. Big data analytics for physical internet-based intelligent manufacturing shop floors. Int. J. Prod. Res. 2017, 55, 2610-2621. [CrossRef]

128. Moyne, J.; Iskandar, J. Big data analytics for smart manufacturing: Case studies in semiconductor manufacturing. Processes 2017, 5, 39. [CrossRef]

129. O'Donovan, P.; Leahy, K.; Bruton, K.; O'Sullivan, D.T. An industrial big data pipeline for data-driven analytics maintenance applications in large-scale smart manufacturing facilities. J. Big Data 2015, 2, 25. [CrossRef]

130. Mani, V.; Delgado, C.; Hazen, B.T.; Patel, P. Mitigating supply chain risk via sustainability using big data analytics: Evidence from the manufacturing supply chain. Sustainability 2017, 9, 608. [CrossRef]

131. Kibria, M.G.; Nguyen, K.; Villardi, G.P.; Zhao, O.; Ishizu, K.; Kojima, F. Big data analytics, machine learning, and artificial intelligence in next-generation wireless networks. IEEE Access 2018, 6, 32328-32338. [CrossRef]

132. Mell, P.; Grance, T. The NIST definition of cloud computing. Nat. Inst. Sci. Technol. 2011, 800, 145.

133. Why Move To The Cloud? 10 Benefits of Cloud Computing. Available online: https://www.salesforce.com/u k/blog/2015/11/why-move-to-the-cloud-10-benefits-of-cloud-computing.html (accessed on 5 April 2020).

134. Aljabre, A. Cloud computing for increased business value. Int. J. Bus. Soc. Sci. 2012, 3, 234-239.

135. Manvi, S.S.; Shyam, G.K. Resource management for Infrastructure as a Service (IaaS) in cloud computing: A survey. J. Netw. Comput. Appl. 2014, 41, 424-440. [CrossRef] 
136. Paraiso, F.; Haderer, N.; Merle, P.; Rouvoy, R.; Seinturier, L. A federated multi-cloud PaaS infrastructure. In Proceedings of the 2012 IEEE Fifth International Conference on Cloud Computing, Honolulu, HI, USA, 24-29 June 2012; IEEE: Piscataway, NJ, USA, 2012; pp. 392-399.

137. Wu, L.; Garg, S.K.; Buyya, R. SLA-based resource allocation for software as a service provider (SaaS) in cloud computing environments. In Proceedings of the 2011 11th IEEE/ACM International Symposium on Cluster, Cloud and Grid Computing, Newport Beach, CA, USA, 23-26 May 2011; IEEE: Piscataway, NJ, USA, 2011; pp. 195-204.

138. Mahali, M.I. Smart door locks based on internet of things concept with mobile backend as a service. Elinvo (Electron. Inform. Vocat. Educ.) 2016, 1, 171-181. [CrossRef]

139. Lynn, T.; Rosati, P.; Lejeune, A.; Emeakaroha, V. A preliminary review of enterprise serverless cloud computing (function-as-a-service) platforms. In Proceedings of the 2017 IEEE International Conference on Cloud Computing Technol. and Sci. (CloudCom), Hong Kong, China, 11-14 December 2017; IEEE: Piscataway, NJ, USA, 2017; pp. 162-169.

140. Baldini, I.; Castro, P.; Chang, K.; Cheng, P.; Fink, S.; Ishakian, V.; Mitchell, N.; Muthusamy, V.; Rabbah, R.; Slominski, A.; et al. Serverless computing: Current trends and open problems. In Research Advances in Cloud Computing; Springer: Singapore, Singapore, 2017; pp. 1-20.

141. Xu, X. From cloud computing to cloud manufacturing. Robot. Comput.-Integr. Manuf. 2012, 28, 75-86. [CrossRef]

142. Liu, Y.; Xu, X.; Zhang, L.; Wang, L.; Zhong, R.Y. Workload-based multi-task scheduling in cloud manufacturing. Robot. Comput.-Integr. Manuf. 2017, 45, 3-20. [CrossRef]

143. Jian, C.F.; Wang, Y. Batch task scheduling-oriented optimization modelling and simulation in cloud manufacturing. Int. J. Simul. Model. 2014, 13, 93-101. [CrossRef]

144. Lartigau, J.; Nie, L.; Xu, X.; Zhan, D.; Mou, T. Scheduling methodology for production services in cloud manufacturing. In Proceedings of the 2012 International Joint Conference on Service Sciences, Shanghai, China, 24-26 May 2012; IEEE: Piscataway, NJ, USA, 2012; pp. 34-39.

145. Tao, F.; Cheng, Y.; Da Xu, L.; Zhang, L.; Li, B.H. CCIoT-CMfg: Cloud computing and internet of things-based cloud manufacturing service system. IEEE Trans. Ind. Inform. 2014, 10, 1435-1442.

146. Jin, H.; Yao, X.; Chen, Y. Correlation-aware QoS modeling and manufacturing cloud service composition. J. Intell. Manuf. 2017, 28, 1947-1960. [CrossRef]

147. Tao, F.; LaiLi, Y.; Xu, L.; Zhang, L. FC-PACO-RM: A parallel method for service composition optimal-selection in cloud manufacturing system. IEEE Trans. Ind. Inform. 2012, 9, 2023-2033. [CrossRef]

148. Tao, F.; Zhang, L.; Venkatesh, V.C.; Luo, Y.; Cheng, Y. Cloud manufacturing: A computing and service-oriented manufacturing model. Proc. Inst. Mech. Eng. Part B J. Eng. Manuf. 2011, 225, 1969-1976. [CrossRef]

149. Oliveira, T.; Thomas, M.; Espadanal, M. Assessing the determinants of cloud computing adoption: An analysis of the manufacturing and services sectors. Inform. Manag. 2014, 51, 497-510. [CrossRef]

150. He, W.; Xu, L. A state-of-the-art survey of cloud manufacturing. Int. J. Comput. Integr. Manuf. 2015, 28, 239-250. [CrossRef]

151. Singhal, A. Data Warehousing and Data Mining Techniques for Cyber Security; Springer Science \& Business Media: Berlin/Heidelberg, Germany, 2007; Volume 31.

152. What is Cyber Security? Available online: https://www.ncsc.gov.uk/section/about-ncsc/what-is-cyber-secur ity (accessed on 5 April 2020).

153. Global Cybersecurity Risks in the Manufacturing Industry. Available online: https://www.willistowerswats on.com/en-US/Insights/2019/07/decode-cyber-brief-global-cybersecurity-risks-in-the-manufacturing-ind ustry (accessed on 5 April 2020).

154. Ani, U.P.D.; He, H.; Tiwari, A. Review of cybersecurity issues in industrial critical infrastructure: Manufacturing in perspective. J. Cyber Secur. Technol. 2017, 1, 32-74. [CrossRef]

155. ISO/IEC 27001 Information Security Management. Available online: https://www.iso.org/isoiec-27001-infor mation-security.html (accessed on 5 April 2020).

156. Wells, L.J.; Camelio, J.A.; Williams, C.B.; White, J. Cyber-physical security challenges in manufacturing systems. Manuf. Lett. 2014, 2, 74-77. [CrossRef]

157. Sturm, L.D.; Williams, C.B.; Camelio, J.A.; White, J.; Parker, R. Cyber-physical vulnerabilities in additive manufacturing systems: A case study attack on the. STL file with human subjects. J. Manuf. Syst. 2017, 44, 154-164. [CrossRef] 
158. Vincent, H.; Wells, L.; Tarazaga, P.; Camelio, J. Trojan detection and side-channel analyses for cyber-security in cyber-physical manufacturing systems. Procedia Manuf. 2015, 1, 77-85. [CrossRef]

159. DeSmit, Z.; Elhabashy, A.E.; Wells, L.J.; Camelio, J.A. 2016, Cyber-physical vulnerability assessment in manufacturing systems. Procedia Manuf. 2015, 5, 1060-1074. [CrossRef]

160. Hutchins, M.J.; Bhinge, R.; Micali, M.K.; Robinson, S.L.; Sutherland, J.W.; Dornfeld, D. Framework for identifying cybersecurity risks in manufacturing. Procedia Manuf. 2015, 1, 47-63. [CrossRef]

161. Tuptuk, N.; Hailes, S. Security of smart manufacturing systems. J. Manuf. Syst. 2018, 47, 93-106. [CrossRef]

162. Wu, D.; Ren, A.; Zhang, W.; Fan, F.; Liu, P.; Fu, X.; Terpenny, J. Cybersecurity for digital manufacturing. J. Manuf. Syst. 2018, 48, 3-12. [CrossRef]

163. Ren, A.; Wu, D.; Zhang, W.; Terpenny, J.; Liu, P. Cyber security in smart manufacturing: Survey and challenges. In IISE Annual Conference Proceedings; Institute of Industrial and Systems Engineers (IISE): Peachtree Corners, GA, USA, 2017; pp. 716-721.

164. Stock, T.; Seliger, G. Opportunities of sustainable manufacturing in industry 4.0. Procedia Cirp 2016, 40, 536-541. [CrossRef]

165. Shafiq, S.I.; Sanin, C.; Szczerbicki, E.; Toro, C. Virtual engineering object/virtual engineering process: A specialized form of cyber physical system for Industrie 4.0. Procedia Comput. Sci. 2015, 60, 1146-1155. [CrossRef]

166. Qin, J.; Liu, Y.; Grosvenor, R. A categorical framework of manufacturing for industry 4.0 and beyond. Procedia Cirp 2016, 52, 173-178. [CrossRef]

167. Zhong, R.Y.; Xu, X.; Klotz, E.; Newman, S.T. Intelligent manufacturing in the context of industry 4.0: A review. Engineering 2017, 3, 616-630. [CrossRef]

168. Kim, D.G.; Park, M.G. Horizontal integration between cyber physical system based on industry 4.0 and manufacture execution systems through middleware building. J. Korea Multimed. Soc. 2014, 17, 1484-1493. [CrossRef]

169. Gerber, T.; Bosch, H.C.; Johnsson, C. Vertical Integration of decision relevant production information into IT-Systems of manufacturing companies. IFAC Proc. Vol. 2012, 45, 811-816. [CrossRef]

170. Bicaku, A.; Maksuti, S.; Palkovits-Rauter, S.; Tauber, M.; Matischek, R.; Schmittner, C.; Mantas, G.; Thron, M.; Delsing, J. Towards trustworthy end-to-end communication in industry 4.0. In Proceedings of the 2017 IEEE 15th International Conference on Industrial Informatics (INDIN), Emden, Germany, 24-26 July 2017; IEEE: Piscataway, NJ, USA, July, 2017; pp. 889-896.

171. Liu, Q.; Chen, J.; Liao, Y.; Mueller, E.; Jentsch, D.; Boerner, F.; She, M. An application of horizontal and vertical integration in cyber-physical production systems. In Proceedings of the 2015 International Conference on Cyber-Enabled Distributed Computing and Knowledge Discovery, Xi'an, China, 17-19 September 2015; IEEE: Piscataway, NJ, USA, 2015; pp. 110-113.

172. Mazak, A.; Huemer, C. HoVer: A modeling framework for horizontal and vertical integration. In Proceedings of the 2015 IEEE 13th International Conference on Industrial Informatics (INDIN), Cambridge, UK, 22-24 July 2015; IEEE: Piscataway, NJ, USA, 2015; pp. 1642-1647.

173. Laurier, W.; Poels, G. Track and trace future, present, and past product and money flows with a resource-event-agent model. Inform. Syst. Manag. 2012, 29, 123-136. [CrossRef]

174. Unver, H.O. An ISA-95-based manufacturing intelligence system in support of lean initiatives. Int. J. Adv. Manuf. Technol. 2013, 65, 853-866. [CrossRef]

175. Zhuo, Y.; Alvarez, C.; Feldmann, K. Horizontal and vertical integration of product data for the design of moulded interconnect devices. Int. J. Comput. Integr. Manuf. 2009, 22, 1024-1036. [CrossRef]

176. Foidl, H.; Felderer, M. Research challenges of industry 4.0 for quality management. In Proceedings of the International Conference on Enterprise Resource Planning Systems, Poznán, Poland, 24-26 June 2015; Springer: Cham, Swizerland; pp. 121-137.

177. ISO. ISO 9000: Quality Management Systems-Fundamentals and Vocabulary (ISO 9000: 2005); International Organization for Standardization: Geneva, Switzerland, 2005; Volume 1.

178. Zhou, K.; Liu, T.; Zhou, L. Industry 4.0: Towards future industrial opportunities and challenges. In Proceedings of the 2015 12th International conference on fuzzy systems and knowledge discovery (FSKD), Chongqing, China, 29-31 May 2012; IEEE: Piscataway, NJ, USA, 2015; pp. 2147-2152.

179. Dalenogare, L.S.; Benitez, G.B.; Ayala, N.F.; Frank, A.G. The expected contribution of Industry 4.0 technologies for industrial performance. Int. J. Prod. Econ. 2018, 204, 383-394. [CrossRef] 
180. Rüßmann, M.; Lorenz, M.; Gerbert, P.; Waldner, M.; Justus, J.; Engel, P.; Harnisch, M. Industry 4.0: The future of productivity and growth in manufacturing industries. Boston Consult. Group 2015, 9, 54-89.

181. Ramayah, T.; Roy, M.H.; Arokiasamy, S.; Zbib, I.; Ahmed, Z.U. Critical success factors for successful implementation of enterprise resource planning systems in manufacturing organisations. Int. J. Bus. Inform. Syst. 2007, 2, 276-297. [CrossRef]

182. Drohomeretski, E.; Gouvea da Costa, S.E.; Pinheiro de Lima, E.; Garbuio, P.A.D.R. Lean, Six Sigma and Lean Six Sigma: An analysis based on operations strategy. Int. J. Prod. Res. 2014, 52, 804-824. [CrossRef]

183. Liverani, A.; Caligiana, G.; Frizziero, L.; Francia, D.; Donnici, G.; Dhaimini, K. Design for Six Sigma (DFSS) for additive manufacturing applied to an innovative multifunctional fan. Int. J. Interact. Des. Manuf. (IJIDeM) 2019, 13, 309-330. [CrossRef]

184. Frank, A.G.; Dalenogare, L.S.; Ayala, N.F. Industry 4.0 technologies: Implementation patterns in manufacturing companies. Int. J. Prod. Econ. 2019, 210, 15-26. [CrossRef]

185. Nenonen, S.; Brodie, R.J.; Storbacka, K.; Peters, L.D. Theorizing with managers: How to achieve both academic rigor and practical relevance? Eur. J. Mark. 2017, 51, 1130-1152. [CrossRef]

186. Feldman, M.S.; Orlikowski, W.J. Theorizing practice and practicing theory. Organ. Sci. 2011, 22, 1240-1253. [CrossRef]

187. Brodie, R.J.; Nenonen, S.; Peters, L.D.; Storbacka, K. Theorizing with managers to bridge the theory-praxis gap. European J. Mark. 2017, 51, 1173-1177. [CrossRef]

188. Weick, K.E. What theory is not, theorizing is. Adm. Sci. Q. 1995, 40, 385-390. [CrossRef]

189. Cornelius, I. Theorizing information for information science. Ann. Rev. Inform. Sci. Technol. 2002, 36, $392-425$. [CrossRef]

190. Browaeys, M.J.; Baets, W. Cultural complexity: A new epistemological perspective. Learn. Organ. 2003, 10, 332-339. [CrossRef]

191. Putnik, G.D.; Browaeys, M.J.; Fisser, S. Lean and agile: An epistemological reflection. Learn. Organ. 2012, 19, 207-218.

192. 11 Known Design for Six Sigma (DFSS) Methodologies. Available online: https://www.scmdojo.com/design -six-sigma-methodologies/ (accessed on 5 April 2020).

193. Jayaram, A. Lean six sigma approach for global supply chain management using industry 4.0 and IIoT. In Proceedings of the 2016 2nd International Conference on Contemporary Computing and Informatics (IC3I), Greater Noida, India, 14-17 December 2016; IEEE: Piscataway, NJ, USA, 2016; pp. 89-94.

194. Arcidiacono, G.; Pieroni, A. The Revolution Lean Six Sigma 4.0. Int. J. Adv. Sci. Eng. Inform. Technol. 2018, 8, 141-149. [CrossRef]

195. Zwikael, O.; Chih, Y.Y.; Meredith, J.R. Project benefit management: Setting effective target benefits. Int. J. Proj. Manag. 2018, 36, 650-658. [CrossRef]

196. Ungerman, O.; Dedkova, J.; Gurinova, K. The impact of marketing innovation on the competitiveness of enterprises in the context of industry 4.0. J. Compet. 2018, 10, 132. [CrossRef]

197. Fernández-Caramés, T.M.; Blanco-Novoa, O.; Froiz-Míguez, I.; Fraga-Lamas, P. Towards an Autonomous Industry 4.0 Warehouse: A UAV and Blockchain-Based System for Inventory and Traceability Applications in Big Data-Driven Supply Chain Management. Sensors 2019, 19, 2394. [CrossRef]

198. Altamony, H.; Al-Salti, Z.; Gharaibeh, A.; Elyas, T. The relationship between change management strategy and successful enterprise resource planning (ERP) implementations: A theoretical perspective. Int. J. Bus. Manag. Econ. Res. 2016, 7, 690-703.

199. Leyh, C.; Schäffer, T.; Bley, K.; Forstenhäusler, S. Assessing the IT and software landscapes of Industry 4.0-Enterprises: The maturity model SIMMI 4.0. In Information Technology for Management: New Ideas and Real Solutions; Springer: Cham, Swizerland, 2016; pp. 103-119.

200. Zarei, M.; Mohammadian, A.; Ghasemi, R. Internet of things in industries: A survey for sustainable development. Int. J. Innov. Sustain. Dev. 2016, 10, 419-442. [CrossRef]

201. Vanpoucke, E.; Vereecke, A.; Muylle, S. Leveraging the impact of supply chain integration through information technology. Int. J. Oper. Prod. Manag. 2017, 37, 510-530. [CrossRef]

202. Cong, L.W.; He, Z. Blockchain disruption and smart contracts. Rev. Financ. Stud. 2019, 32, $1754-1797$. [CrossRef]

203. Tupa, J.; Simota, J.; Steiner, F. Aspects of risk management implementation for Industry 4.0. Procedia Manuf. 2017, 11, 1223-1230. [CrossRef] 
204. Kelley, S.W.; Turley, L.W. Consumer perceptions of service quality attributes at sporting events. J. Bus. Res. 2001, 54, 161-166. [CrossRef]

205. Bolar, A.A.; Tesfamariam, S.; Sadiq, R. Framework for prioritizing infrastructure user expectations using Quality Function Deployment (QFD). Int. J. Sustain. Built Environ. 2017, 6, 16-29. [CrossRef]

206. Martí Bigorra, A.; Isaksson, O. Combining customer needs and the customer's way of using the product to set customer-focused targets in the House of Quality. Int. J. Prod. Res. 2017, 55, 2320-2335. [CrossRef]

207. Goedhart, R.; Schoonhoven, M.; Does, R.J. Guaranteed in-control performance for the Shewhart X and X control charts. J. Qual. Technol. 2017, 49, 155-171. [CrossRef]

208. Tran, K.P.; Castagliola, P.; Celano, G. Monitoring the ratio of population means of a bivariate normal distribution using CUSUM type control charts. Stat. Pap. 2018, 59, 387-413. [CrossRef]

209. Meudt, T.; Metternich, J.; Abele, E. Value stream mapping 4.0: Holistic examination of value stream and information logistics in production. CIRP Ann. 2017, 66, 413-416. [CrossRef]

210. An Industry 4 Readiness Assessment Tool. Available online: https://warwick.ac.uk/fac/sci/wmg/research/sci p/reports/final_version_of_i4_report_for_use_on_websites.pdf (accessed on 10 April 2020).

211. Industry 4.0 Readiness Online Self-Check for Businesses. Available online: https://www.industrie40-readin ess.de/?lang=en (accessed on 10 April 2020).

212. Available online: https://i4--0-self-assessment.pwc.nl/i40/landing/ (accessed on 10 April 2020).

213. Industry4WRD. Available online: https://www.miti.gov.my/miti/resources/National\%20Policy\%20on\%20In dustry\%204.0/Industry4WRD_Booklet.pdf (accessed on 10 April 2020).

214. Akay, D.; Demiray, A.; Kurt, M. Collaborative tool for solving human factors problems in the manufacturing environment: The Theory of Inventive Problem Solving Technique (TRIZ) method. Int. J. Prod. Res. 2008, 46, 2913-2925. [CrossRef]

215. Aithal, P.S.; Kumar, P.M. Using six thinking hats as a tool for lateral thinking in organizational problem solving. Int. J. Eng. Res. Mod. Educ. (IJERME) 2016, 1, 225-234.

216. Butt, J.; Jedi, S. Redesign of an In-Market Conveyor System for Manufacturing Cost Reduction and Design Efficiency Using DFMA Methodology. Designs 2020, 4, 6. [CrossRef]

217. Begam, M.S.; Swamynathan, R.; Sekkizhar, J. Current trends on lean management-A review. Int. J. Lean Think. 2013, 4, 15-21.

218. Gen, M.; Lin, L. Multiobjective evolutionary algorithm for manufacturing scheduling problems: State-of-the-art survey. J. Intell. Manuf. 2014, 25, 849-866. [CrossRef]

219. Sukthomya, W.; Tannock, J. The optimisation of neural network parameters using Taguchi's design of experiments approach: An application in manufacturing process modelling. Neural Comput. Appl. 2005, 14, 337-344. [CrossRef]

220. Braimah, M.N.; Anozie, A.N.; Odejobi, O.J. Utilization of Response sUrface Methodology (RSM) in the Optimization of Crude Oil Refinery Process, New Port-Harcourt Refinery, Nigeria. J. Eng. Sci. Technol. 2016, 3, 4361-4369.

221. Available online: https://sixsigmastudyguide.com/pilot-plan/ (accessed on 10 April 2020).

222. Antony, J.; Kumar, M.; Labib, A. Gearing Six Sigma into UK manufacturing SMEs: Results from a pilot study. J. Oper. Res. Soc. 2008, 59, 482-493. [CrossRef]

223. Georgoulias, K.; Papakostas, N.; Chryssolouris, G.; Stanev, S.; Krappe, H.; Ovtcharova, J. Evaluation of flexibility for the effective change management of manufacturing organizations. Robot. Comput.-Integr. Manuf. 2009, 25, 888-893. [CrossRef]

224. Leach, L. Schedule and cost buffer sizing: How to account for the bias between project performance and your model. Proj. Manag. J. 2003, 34, 34-47. [CrossRef]

225. Carroll, B. Leadership in lean, empowering manufacturing organizations. J. Organ. Excell. 2001, 20, 81-90. [CrossRef]

226. May, G.; Stahl, B. The significance of organizational change management for sustainable competitiveness in manufacturing: Exploring the firm archetypes. Int. J. Prod. Res. 2017, 55, 4450-4465. [CrossRef]

227. Six Sigma Study Guide. Available online: https://sixsigmastudyguide.com/implementation-plan/ (accessed on 10 April 2020).

228. The Power of Kaizen Teams. Available online: https://www.kaizen-news.com/the-power-of-kaizen-teams/ (accessed on 10 April 2020). 
229. García, J.L.; Rivera, D.G.; Iniesta, A.A. Critical success factors for Kaizen implementation in manufacturing industries in Mexico. Int. J. Adv. Manuf. Technol. 2013, 68, 537-545. [CrossRef]

230. Glover, W.J.; Farris, J.A.; Van Aken, E.M.; Doolen, T.L. Critical success factors for the sustainability of Kaizen event human resource outcomes: An empirical study. Int. J. Prod. Econ. 2011, 132, 197-213. [CrossRef]

(C) 2020 by the author. Licensee MDPI, Basel, Switzerland. This article is an open access article distributed under the terms and conditions of the Creative Commons Attribution (CC BY) license (http://creativecommons.org/licenses/by/4.0/). 